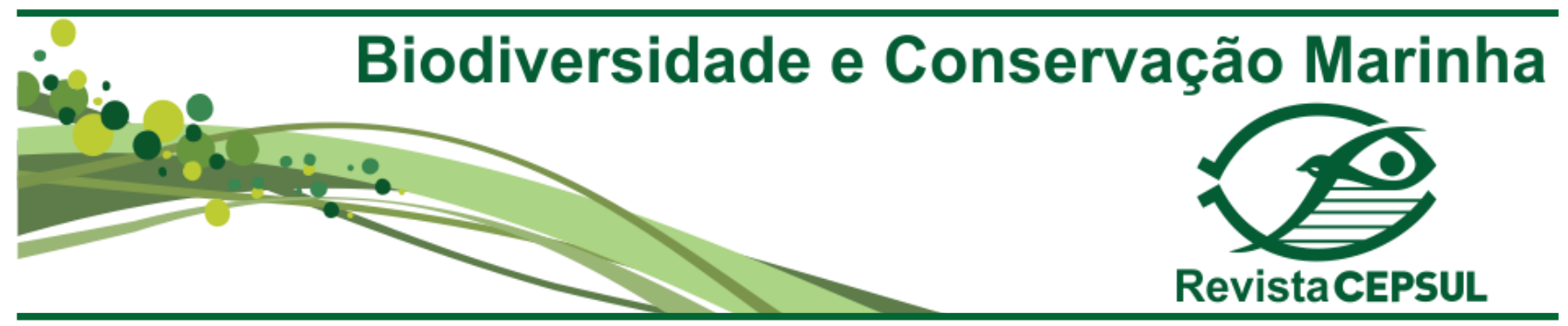

ARTIGO DE REVISÃO - ESPECIAL BABITONGA

\title{
Zooplâncton da Baía da Babitonga e plataforma continental adjacente: diagnóstico e revisão bibliográfica
}

\author{
Miodeli Nogueira-JÚnioR ${ }^{1} \&$ Micheli Duarte de Paula Costa ${ }^{2}$
}

\begin{abstract}
${ }^{1}$ Departamento de Sistemática e Ecologia, Universidade Federal da Paraíba - UFPB, Cidade Universitária, CEP - 58051-90o , João Pessoa,PB, Brasil, miodeli@gmail.com;

${ }_{2}^{2}$ School of Biological Sciences, The University of Queensland, St Lucia, QLD 4072, Australia; duarte.micheli@yahoo.com.br.
\end{abstract}

\author{
Submetido em: o7/o3/2017; Aceito em: 31/o1/2018; Publicado em: 14/o1/2019
}

\begin{abstract}
Resumo. O zooplâncton é um importante elo nas teias tróficas aquáticas, além de representar uma parcela considerável da biodiversidade. No presente estudo revisamos o conhecimento sobre a comunidade zooplanctônica no estuário da Babitonga e áreas costeiras adjacentes visando fornecer subsídios para elaboração de planos de conservação e manejo locais. O estudo do zooplâncton na região é recente, desde 2002, com maior esforço amostral no canal principal do estuário. Um total de 261 espécies foram registrados até o momento, sendo 159 invertebrados e 102 larvas de peixes, incluindo sete espécies exóticas. A região ainda carece de estudos, principalmente nas áreas mais internas do estuário, bem como para diversos grupos taxonômicos (e.g. moluscos, quetognatos, apendiculárias) e aspectos como interações tróficas e simbióticas, reprodução, produção secundária, dinâmica populacional, padrões de flutuação em curto e longo-prazo, e a influência de eventos climáticos e mudanças climáticas na composição, distribuição e abundância das espécies.
\end{abstract}

Palavras-chave: medusas, copépodes, larvas de decápoda, ictioplâncton, meroplâncton, holoplâncton.

\begin{abstract}
Zooplankton of Babitonga Bay and adjacent continental shelf: diagnosis and literature review. Zooplankton is an important link within aquatic food webs and represents a large fraction of the biodiversity. Here we review the zooplankton literature from Babitonga Bay estuary and adjacent coastal area in order to provide technical background for the elaboration of local conservation and management policies. Zooplankton studies in the area are recent, since 2002, with higher sampling effort in the main channel of the estuary. A total of 261 species have been recorded, with 159 invertebrates and 102 fish larvae, including seven exotic species. Local zooplankton studies are yet limited, particularly in the inner regions of the estuary, as well as for many taxonomic groups (e.g. mollusks, chaetognaths, appendicularians) and for aspects such as trophic and symbiotic interactions, reproduction, secondary production, population dynamics, short- and long-term dynamics, and the influence of climate events and climate change in the species composition, distribution and abundance.
\end{abstract}

Keywords: medusae, copepods, decapod larvae, ichthyoplankton, meroplankton, holoplankton. 


\section{Introdução}

O zooplâncton representa um importante compartimento das comunidades aquáticas, sendo composto por animais adaptados à vida em suspensão na coluna de água e com capacidade de locomoção limitada em relação à força de turbulência das correntes, sendo, portanto, transportados passivamente pelas correntes (e.g. Lalli \& Parsons, 1997). Esses animais controlam a produção fitoplanctônica, principal fonte de produtividade primária marinha sendo, portanto, cruciais na transferência de energia entre os produtores primários e os demais níveis tróficos nos ecossistemas marinhos, sustentando assim, direta ou indiretamente, populações de peixes, muitos dos quais de importância comercial. A abundância, diversidade e estrutura da comunidade zooplanctônica é determinante na estruturação das teias tróficas e, portanto, no funcionamento dos ecossistemas marinhos e estuarinos e nos ciclos biogeoquímicos (Harris et al., 2000; Vieira et al., 2015). Além disso, o zooplâncton é bastante diversificado, tanto ecologicamente quanto morfológica e taxonomicamente, representando uma importante parcela da biodiversidade marinha (Boltovskoy, 1981, 1999) e destacando-se tanto pelo elevado número de espécies quanto de grupos taxonômicos de categorias superiores. Praticamente todos os filos animais têm representantes planctônicos pelo menos em algum estágio do ciclo de vida, incluindo o subfilo dos vertebrados já que os estágios de ovo e/ou larva da maioria dos peixes ósseos marinhos habita o plâncton (Boltovskoy, 1981, 1999; Harris et al., 2000).

Considerando a permanência no plâncton, os organismos são classificados como holoplâncton e meroplâncton. O holoplâncton constitui as espécies que passam todo o seu ciclo de vida no plâncton (e.g. copépodes, sifonóforos, ctenóforos, eufausiáceos, quetognatos, apendiculárias, taliáceos), enquanto o meroplâncton engloba os organismos que passam somente parte do seu ciclo de vida no plâncton (e.g. alguns grupos de medusas, larvas de organismos bênticos como decápodes, moluscos, poliquetas, etc., e ictioplâncton). O ictioplâncton compreende os ovos e larvas de peixes tele- ósteos, representando assim o componente com importância econômica mais direta da comunidade zooplanctônica juntamente com as larvas de decápodes (Smith \& Johnson, 1996, Sumich 1996, Lalli \& Parsons, 1997). A sobrevivência, crescimento, dispersão e recrutamento dessas larvas controla amplamente a distribuição e dinâmica populacional dos adultos.

Em geral, o zooplâncton tem um ciclo de vida curto, respondendo rapidamente às mudanças ambientais (Lalli \& Parsons, 1997; Harris et al., 2000). Assim, sua distribuição e abundância refletem padrões temporais e espaciais de acordo com as flutuações ambientais e com os processos de mistura da coluna d'água (Boltovskoy, 1981, 1999). Desta maneira, os organismos zooplanctônicos respondem rápido a alterações no ambiente, sejam elas naturais ou antrópicas, sendo em geral considerados bons indicadores da qualidade ambiental.

No presente trabalho apresentamos uma revisão sobre o conhecimento da comunidade zooplanctônica da Baía da Babitonga e plataforma continental rasa adjacente, região conhecida como "Ecossistema Babitonga” (sensu Gerhardinger et al., 2016), particularmente visando fornecer subsídios técnicos sobre esse importante compartimento para auxiliar no diagnóstico do ambiente natural da região com vistas a elaboração de um plano de manejo e conservação desse importante ecossistema (veja Gerhardinger et al., 2016, 2018 para uma descrição detalhada do Ecossistema Babitonga).

\section{Metodologia}

As informações presentes neste estudo foram levantadas da literatura, pela experiência prévia dos autores em projetos na região (e.g. Costa \& Souza-Conceição, 2009; Nogueira -Júnior \& Souza-Conceição, 2010; Costa, 2011; Costa et al., 2011, 2012; Nogueira-Júnior, 2012; Nogueira-Júnior et al., 2015; Nogueira-Júnior \& Oliveira, 2017), e através de buscas na internet usando o Google acadêmico e a Plataforma Lattes (http://lattes.cnpq.br/). As buscas fo- 
ram realizadas até fevereiro de 2017 utilizando combinações de palavras como "zooplâncton", "Baía da Babitonga", "São Francisco do Sul”, "Itapoá", "Copepoda”, "ictioplâncton", "larvas", "crustáceos", "medusas". Considerando a baixa quantidade de estudos com o zooplâncton da região foram considerados todos os trabalhosdisponíveis, incluindo não publicados como teses, dissertações, trabalhos de conclusão de curso de graduação e resumos de congressos. Uma tabela com todas as espécies registradas foi compilada (Tabela 1). Considerando que os estudos com o zooplâncton do ecossistema Babitonga são bastante recentes, foram divididos em apenas dois períodos de similar intervalo, de 2002 a 2009 e de 2010 a fevereiro de 2017.

\section{Resultados e discussão}

\section{Estudos na região}

O estudo do zooplâncton do Ecossistema Babitonga é bastante recente (Schettini et al., 2002) e restrito e, portanto, não existe muita informação sobre esse importante compartimento ainda que o conhecimento da diversidade, abundância e dinâmica espaçotemporal do zooplâncton da região venha aumentando consideravelmente (e.g. MarafonAlmeida et al., 2008a; Souza-Conceição et al., 2013a, b). Apenas 40 estudos foram realizados com o zooplâncton no ecossistema Babitonga, sete deles na plataforma e o resto exclusivamente dentro do estuário. O esforço amostral foi consideravelmente maior no canal principal do estuário, pequeno na plataforma adjacente e praticamente inexistente nos canais internos (Figura 1) com salinidades mais baixas $(<10)$.

A maior parte desses estudos foi divulgada através de artigos em revistas científicas indexadas $(32,5 \%)$ e resumos de congressos (30\%; Figura 2a), seguidos por Trabalhos de Conclusão de Curso de Graduação (TCCs; 18\%). O número de artigos acadêmicos em revistas científicas aumentou consideravelmente

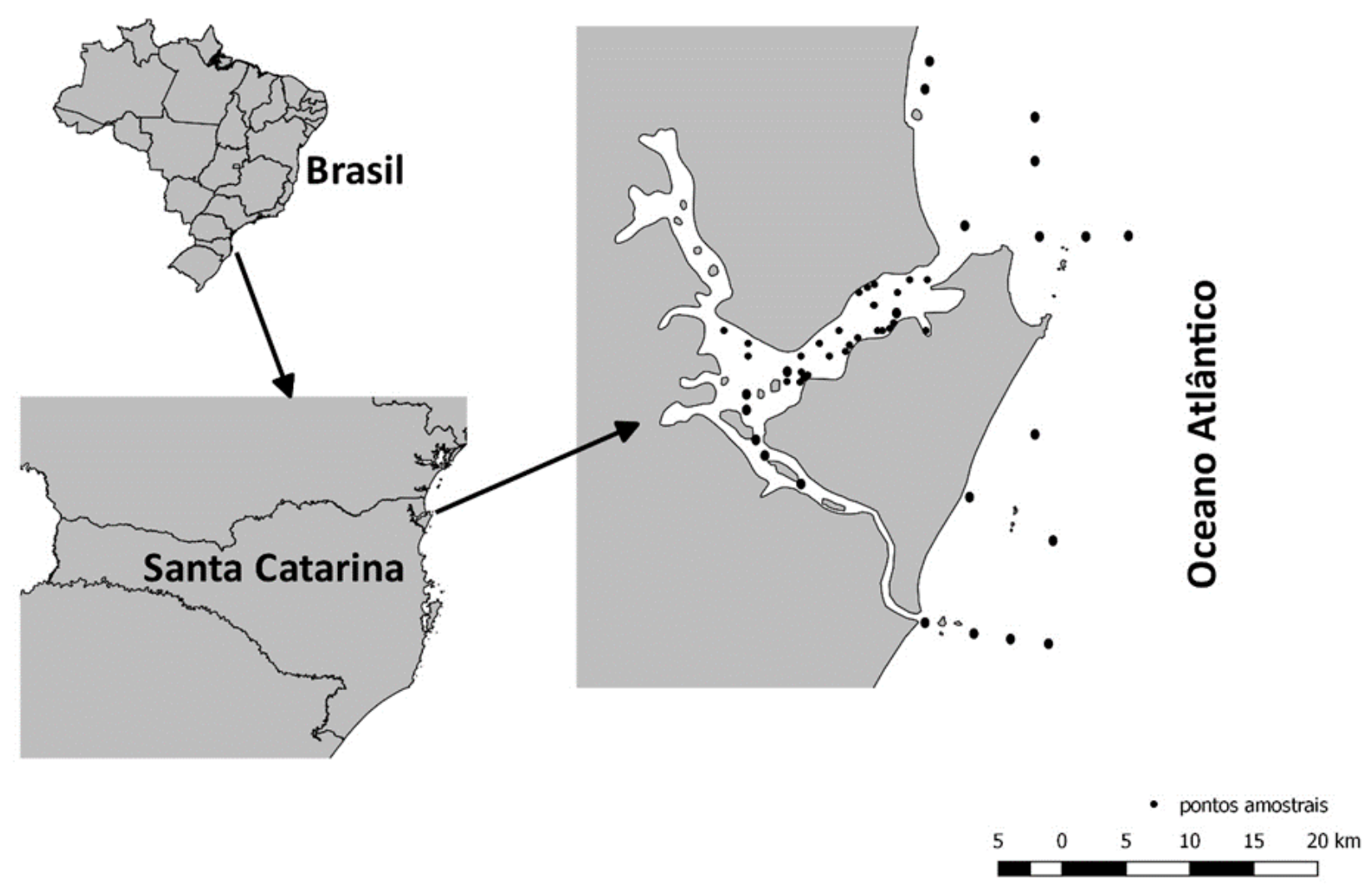

Figura 1. Mapa da Baía da Babitonga e plataforma adjacente mostrando os pontos de coleta dos estudos com metazoários planctônicos na região. 


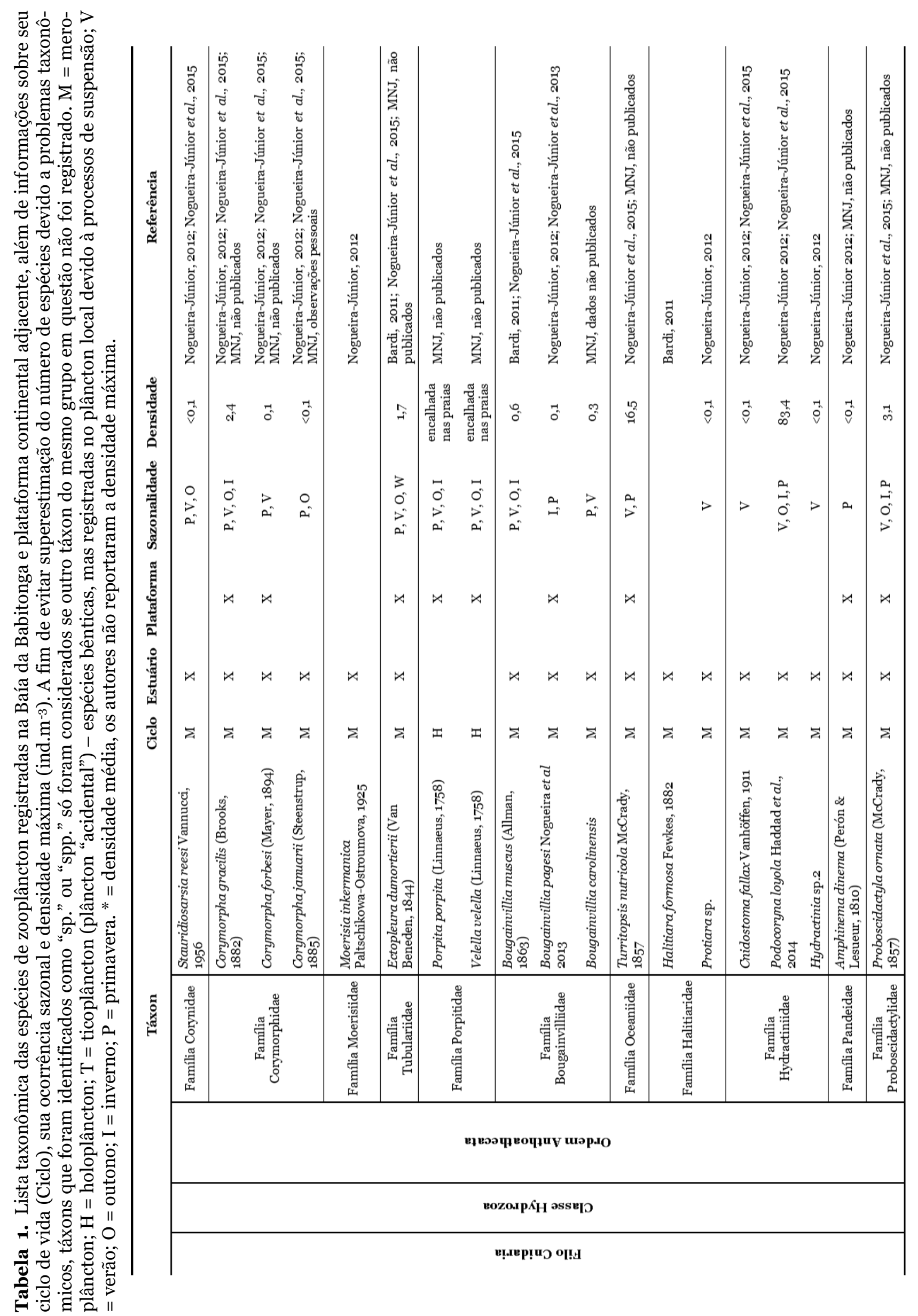




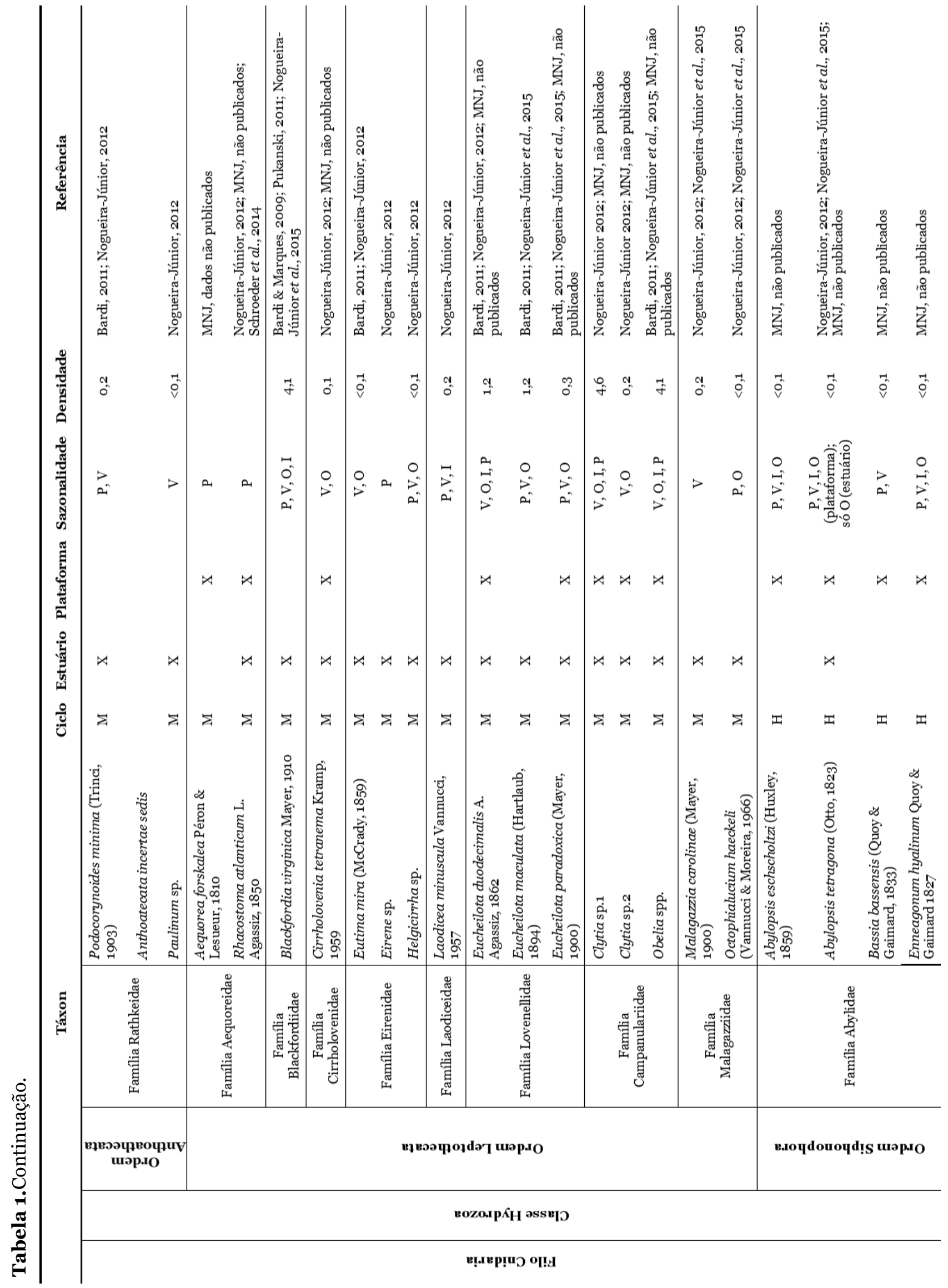




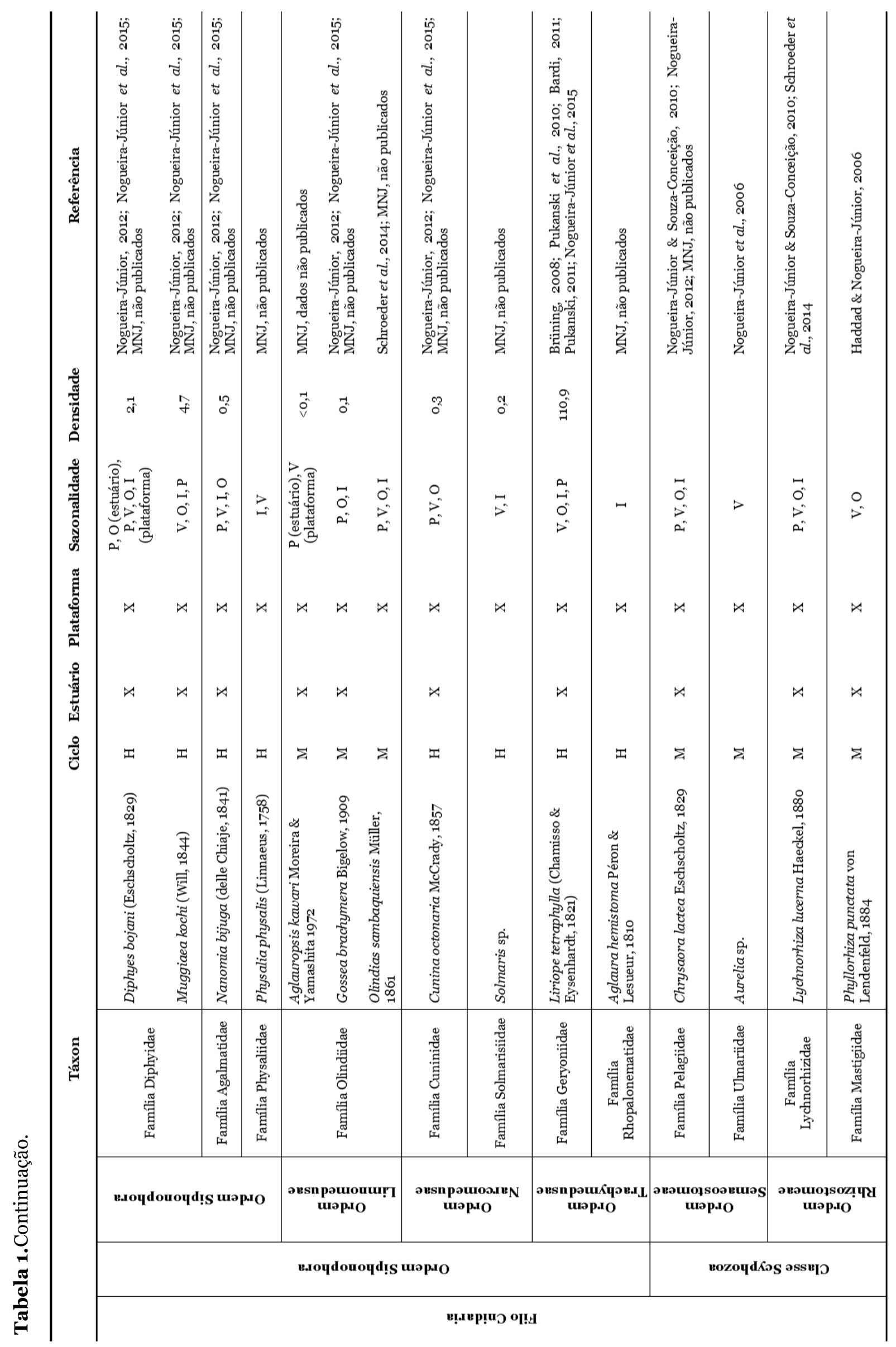

Revista CEPSUL - Biodiversidade e Conservação Marinha, 8: eb2019oo1 


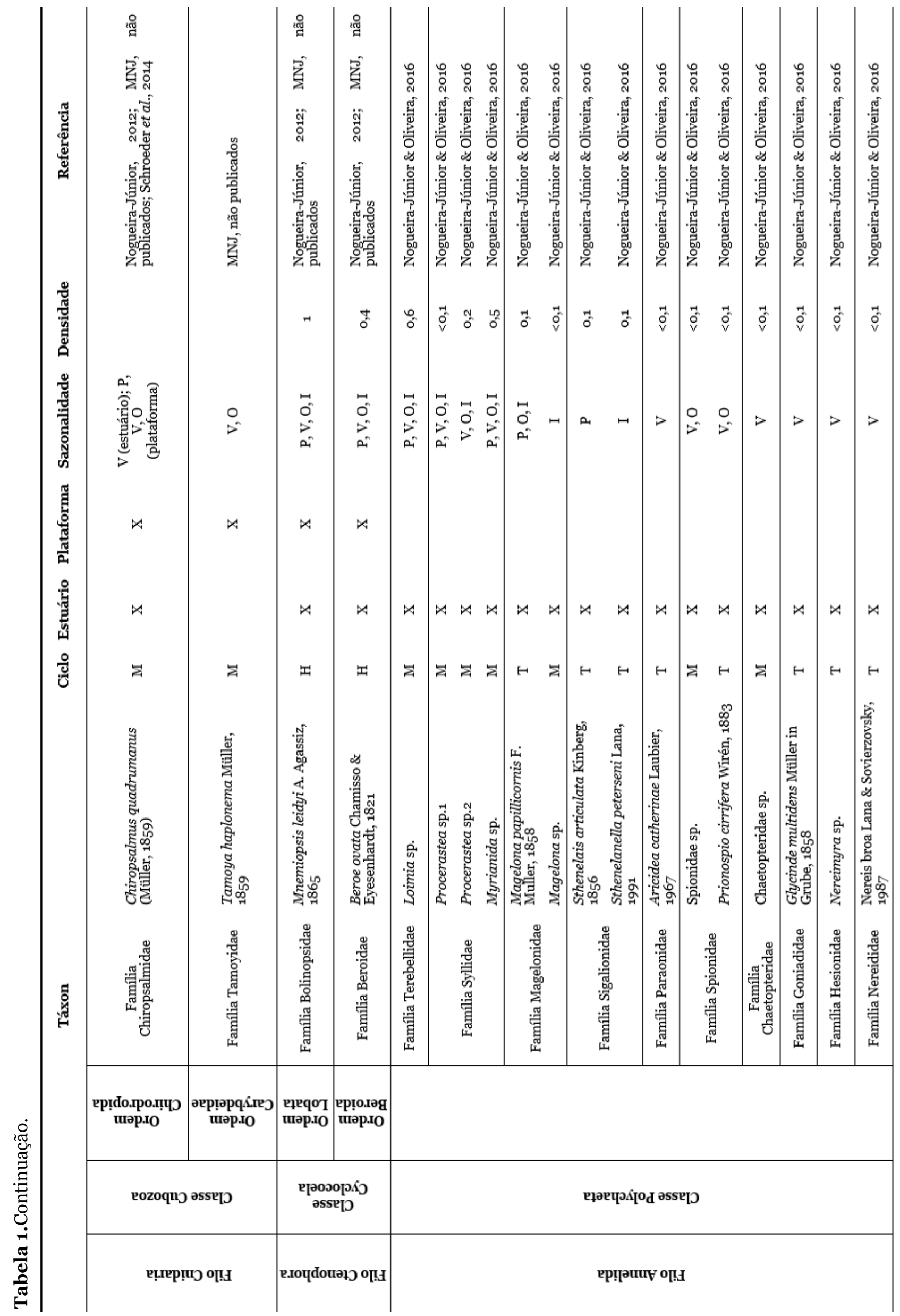




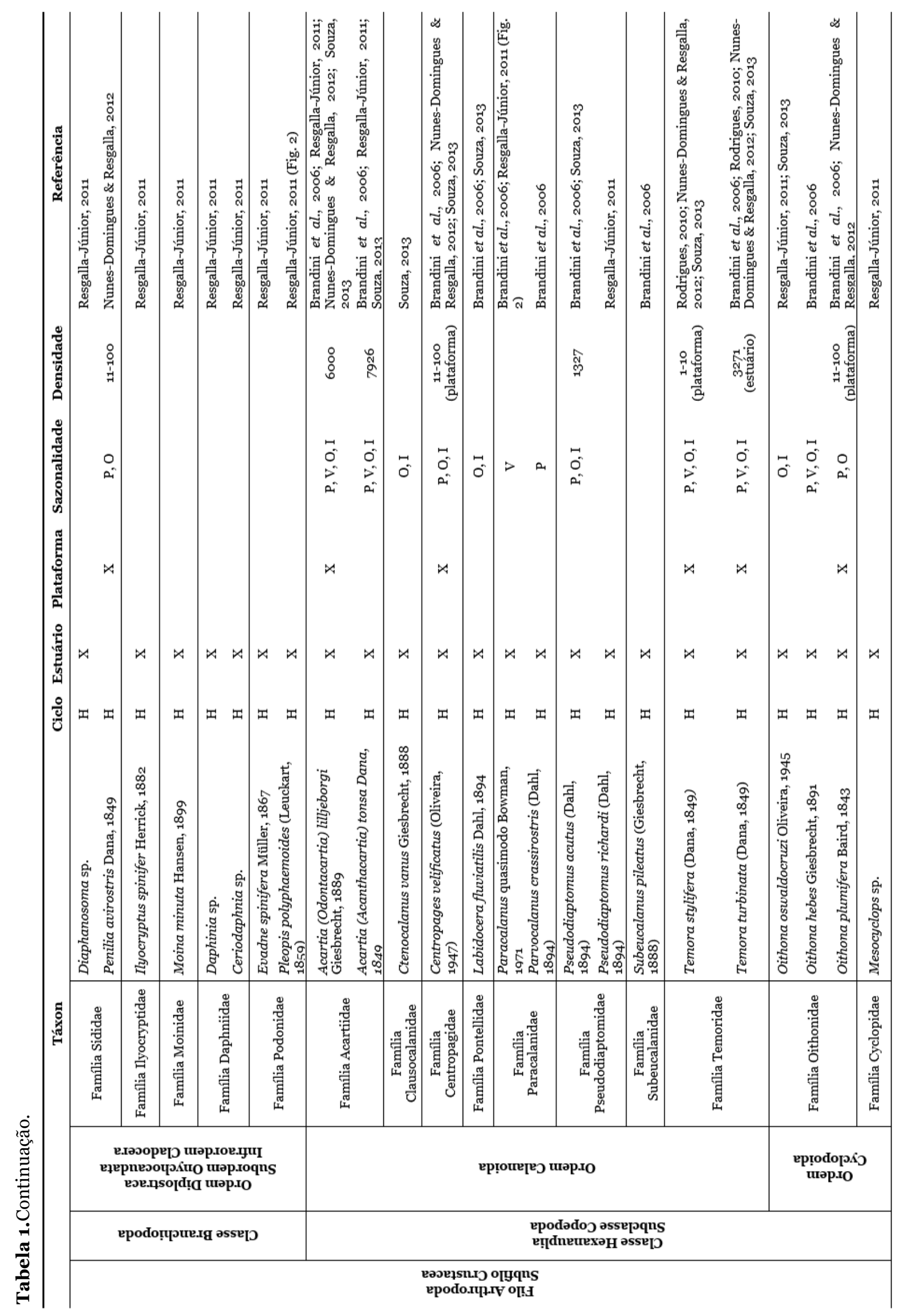

Revista CEPSUL - Biodiversidade e Conservação Marinha, 8: eb2019oo1 


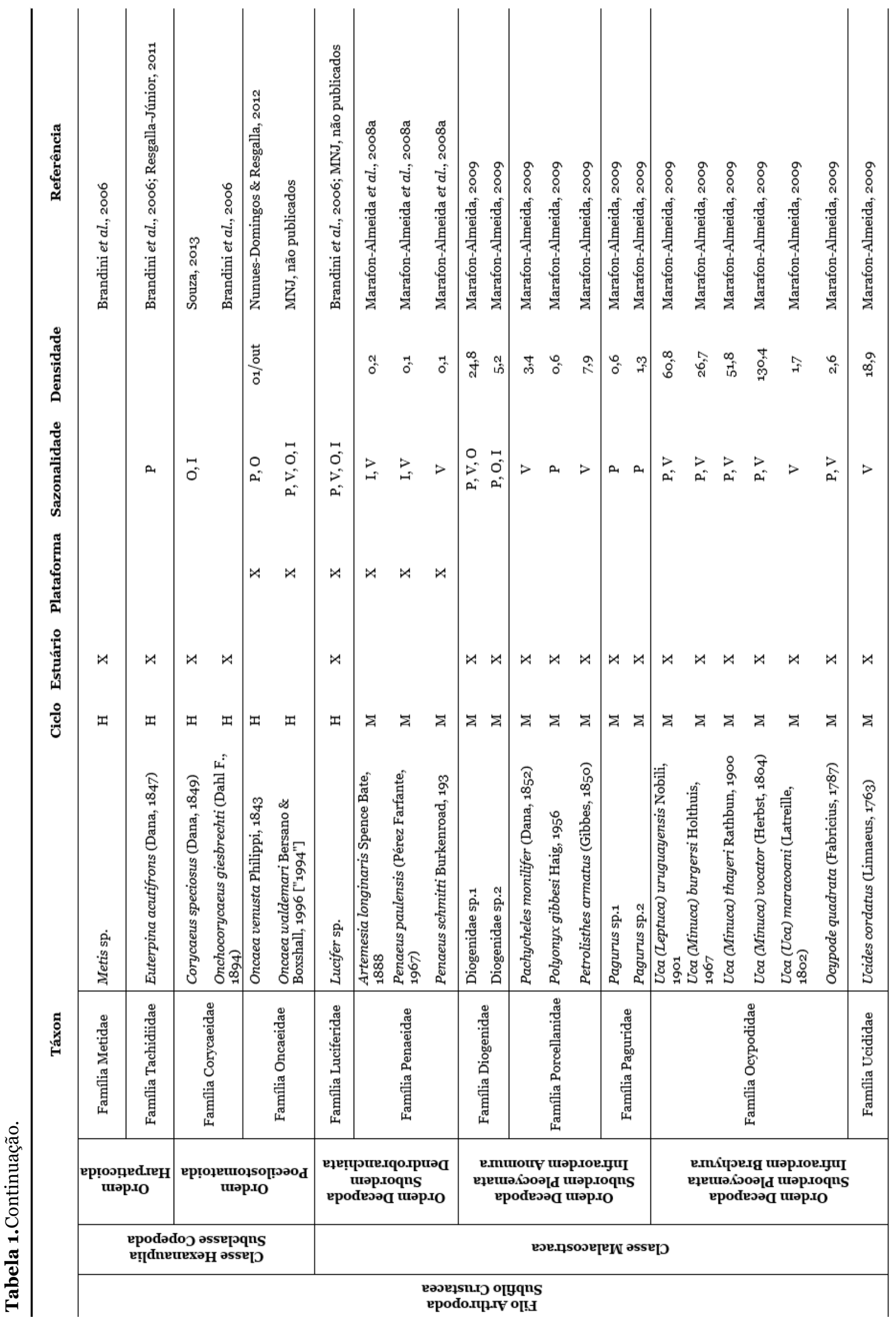




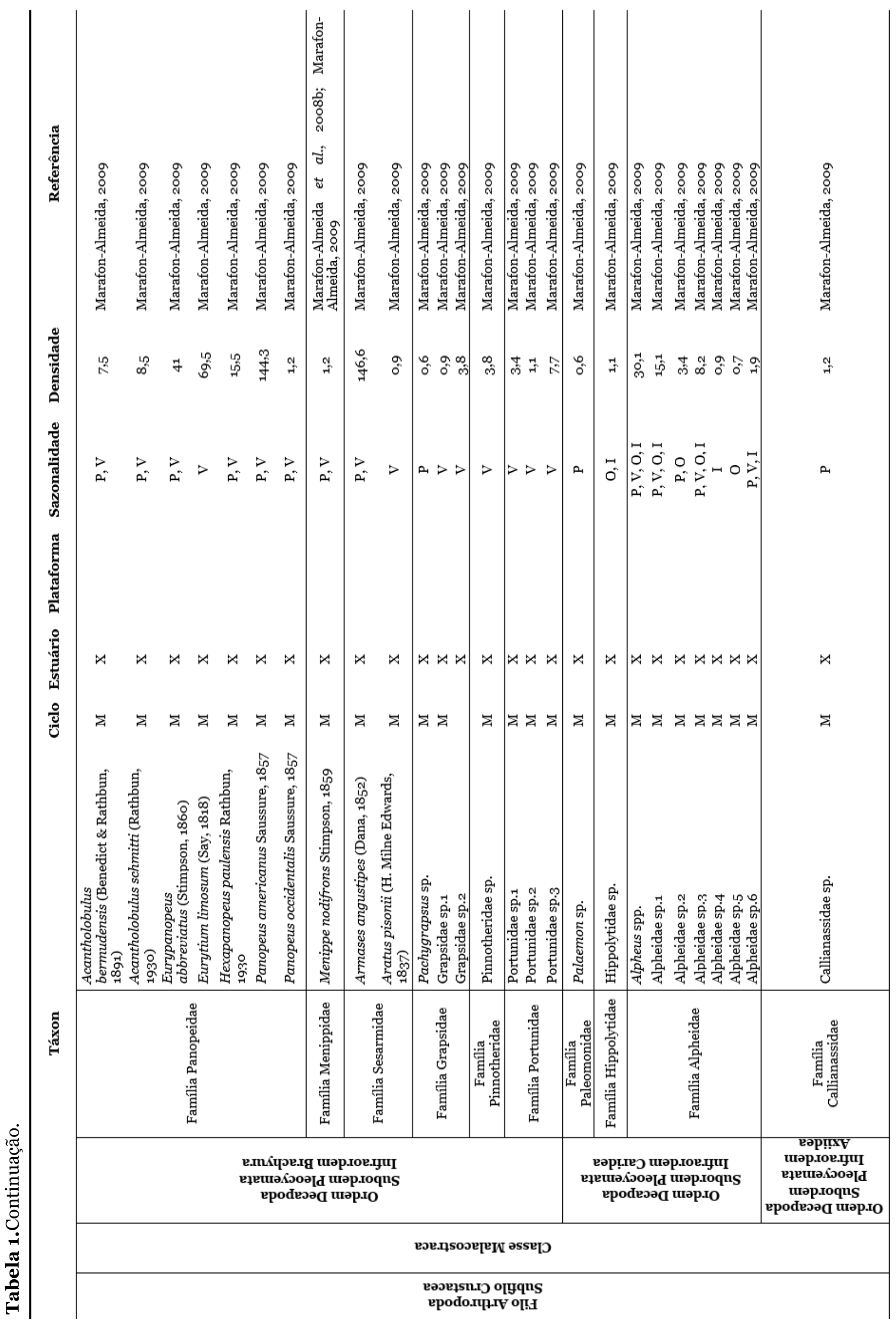

Revista CEPSUL - Biodiversidade e Conservação Marinha, 8: eb2019oo1 


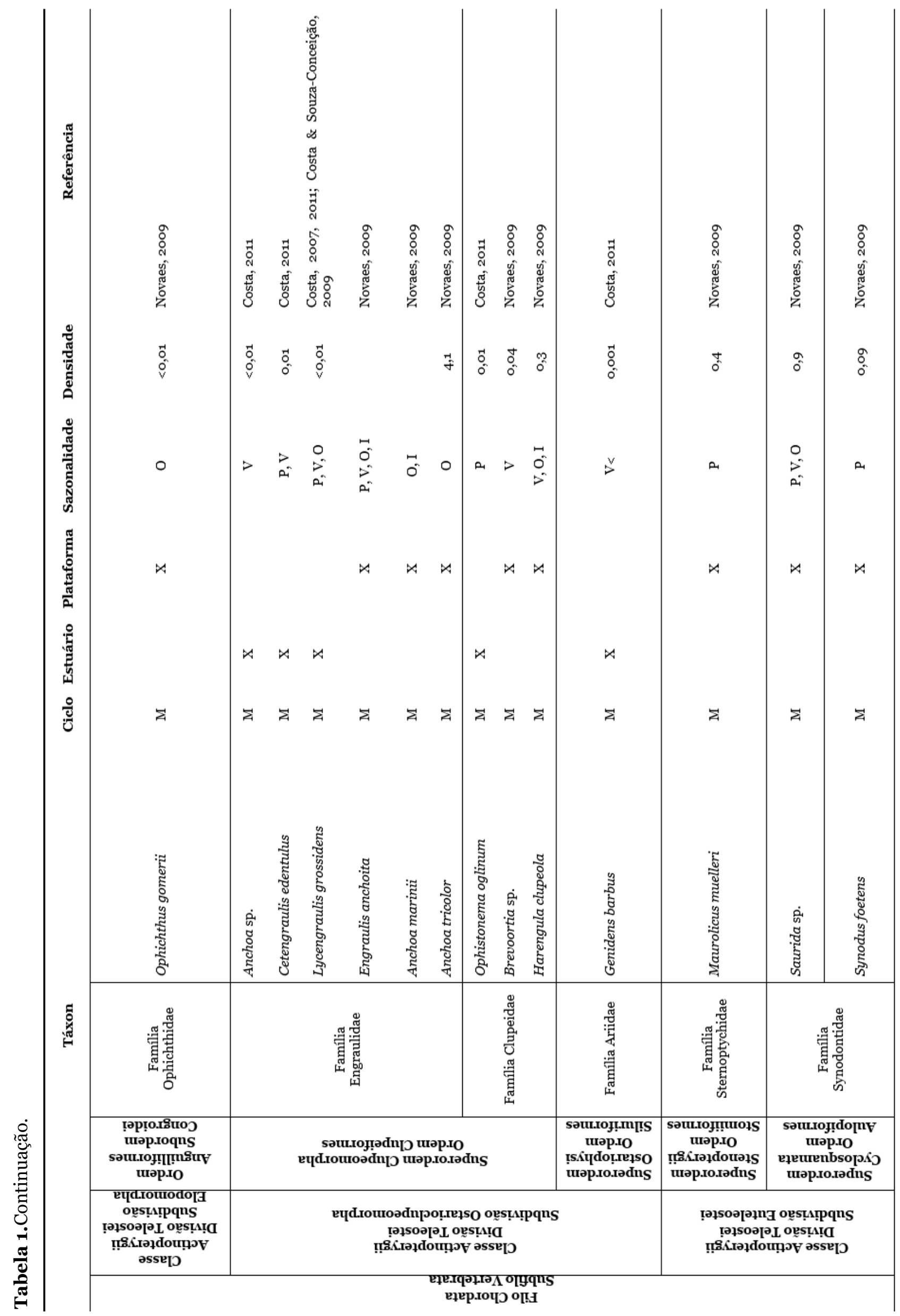




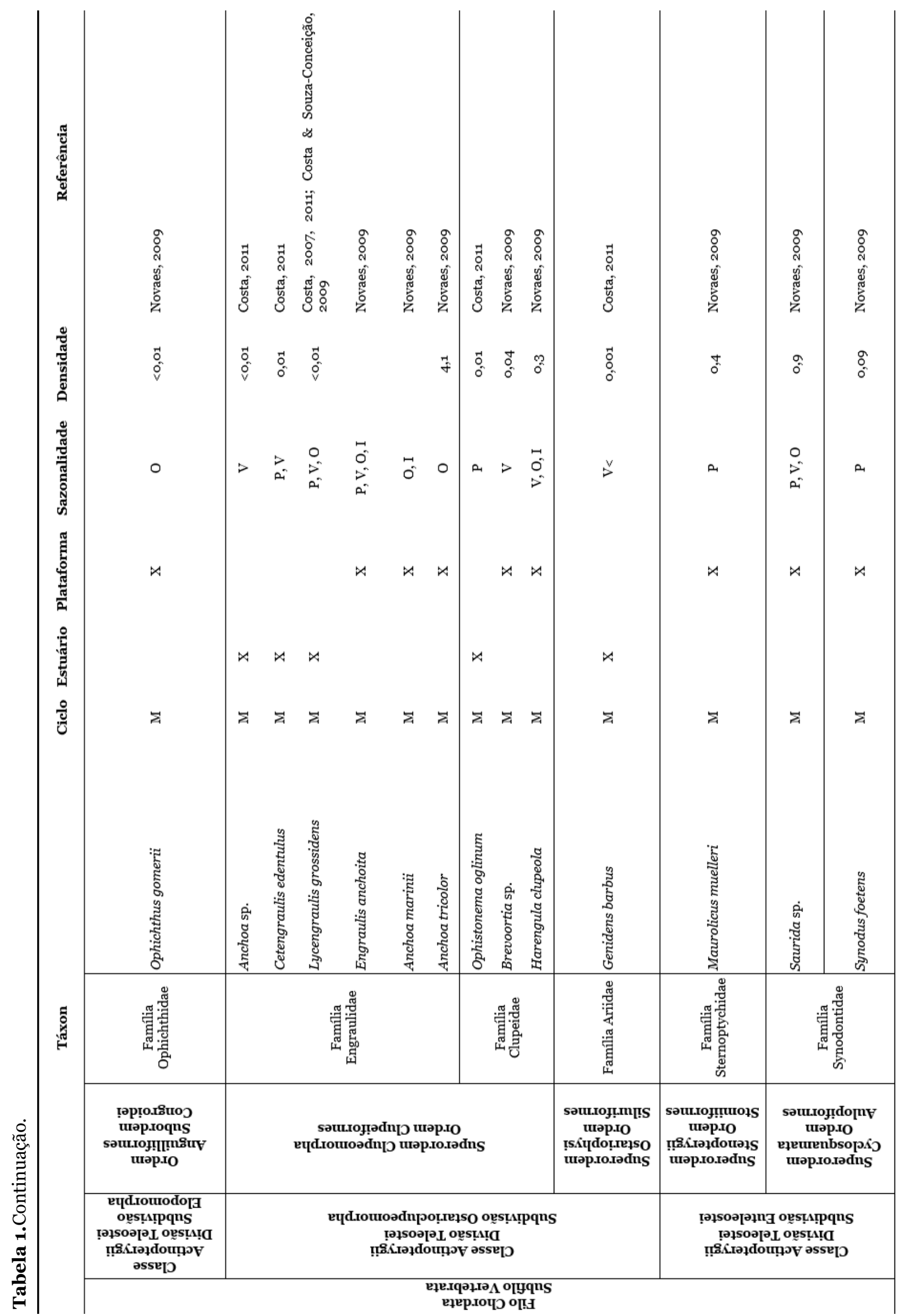

Revista CEPSUL - Biodiversidade e Conservação Marinha, 8: eb2019oo1 


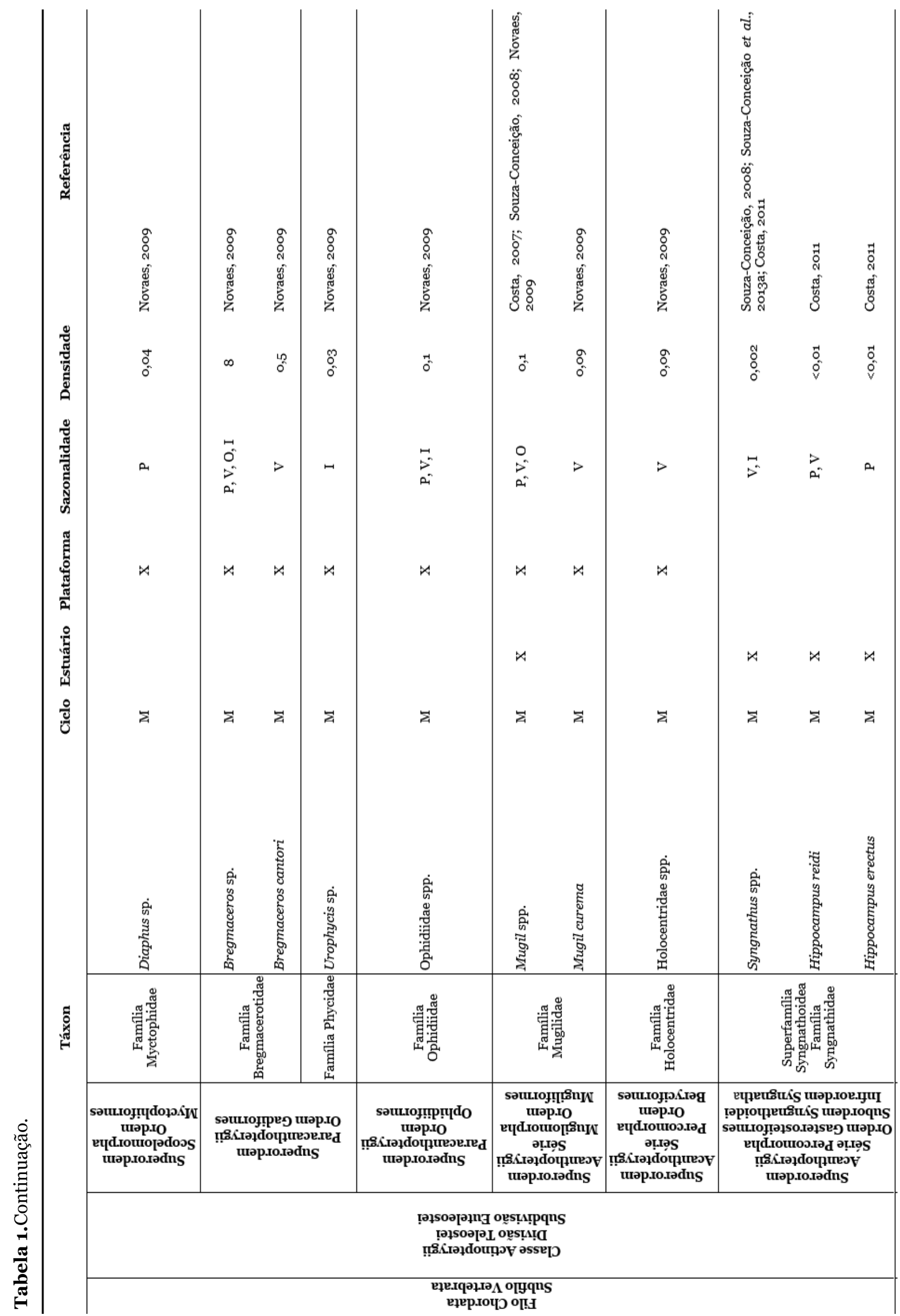




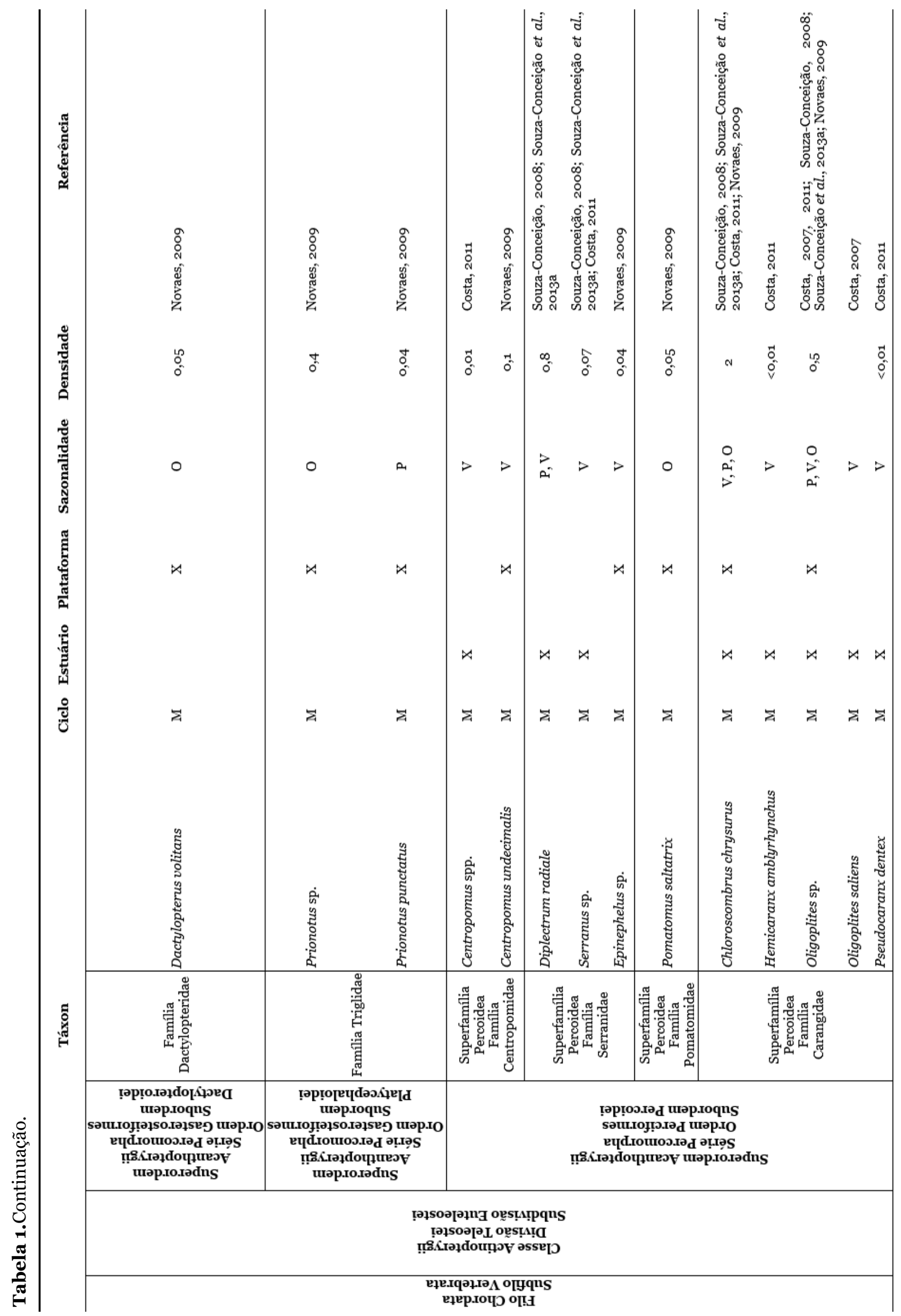

Revista CEPSUL - Biodiversidade e Conservação Marinha, 8: eb2019oo1 


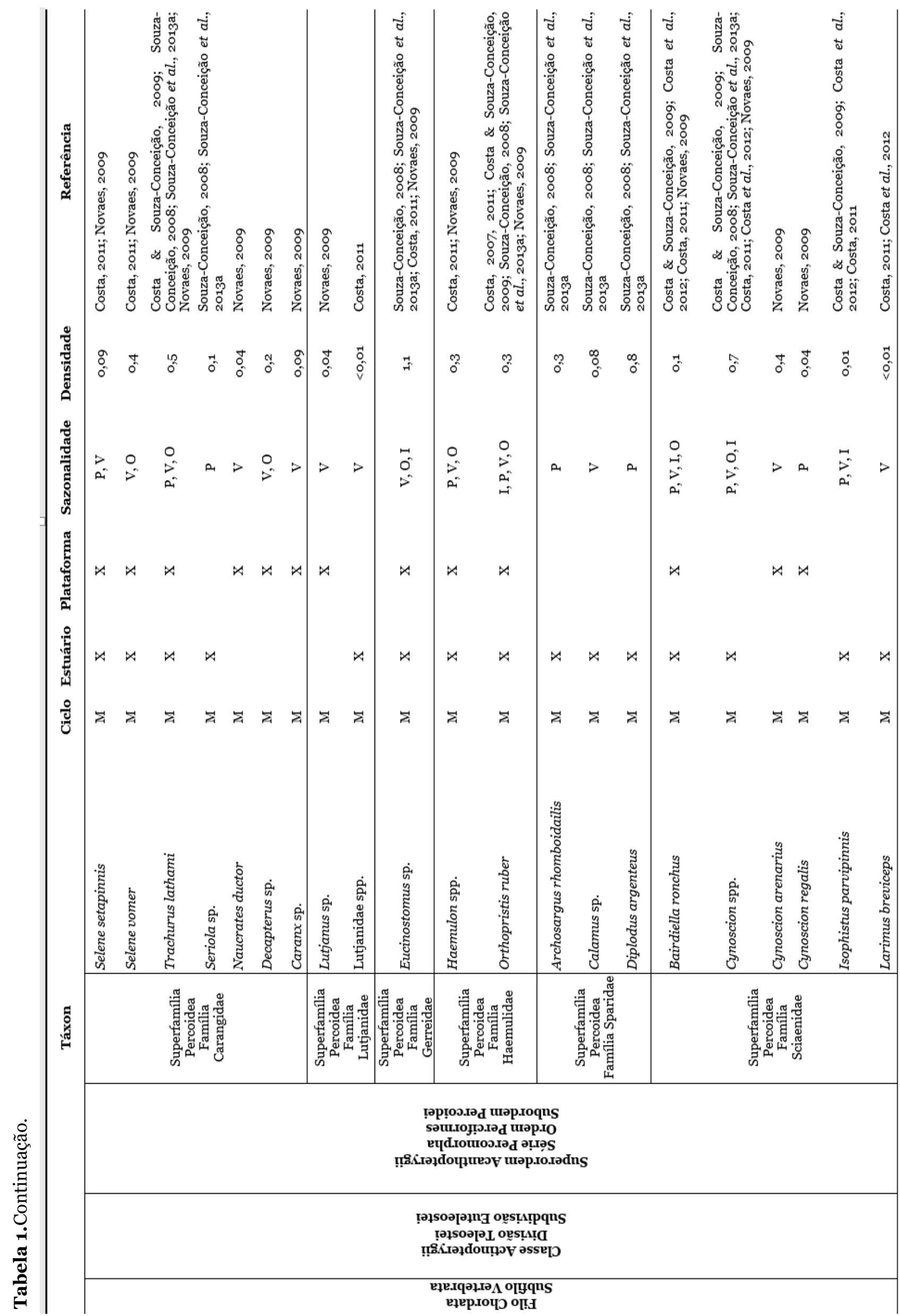




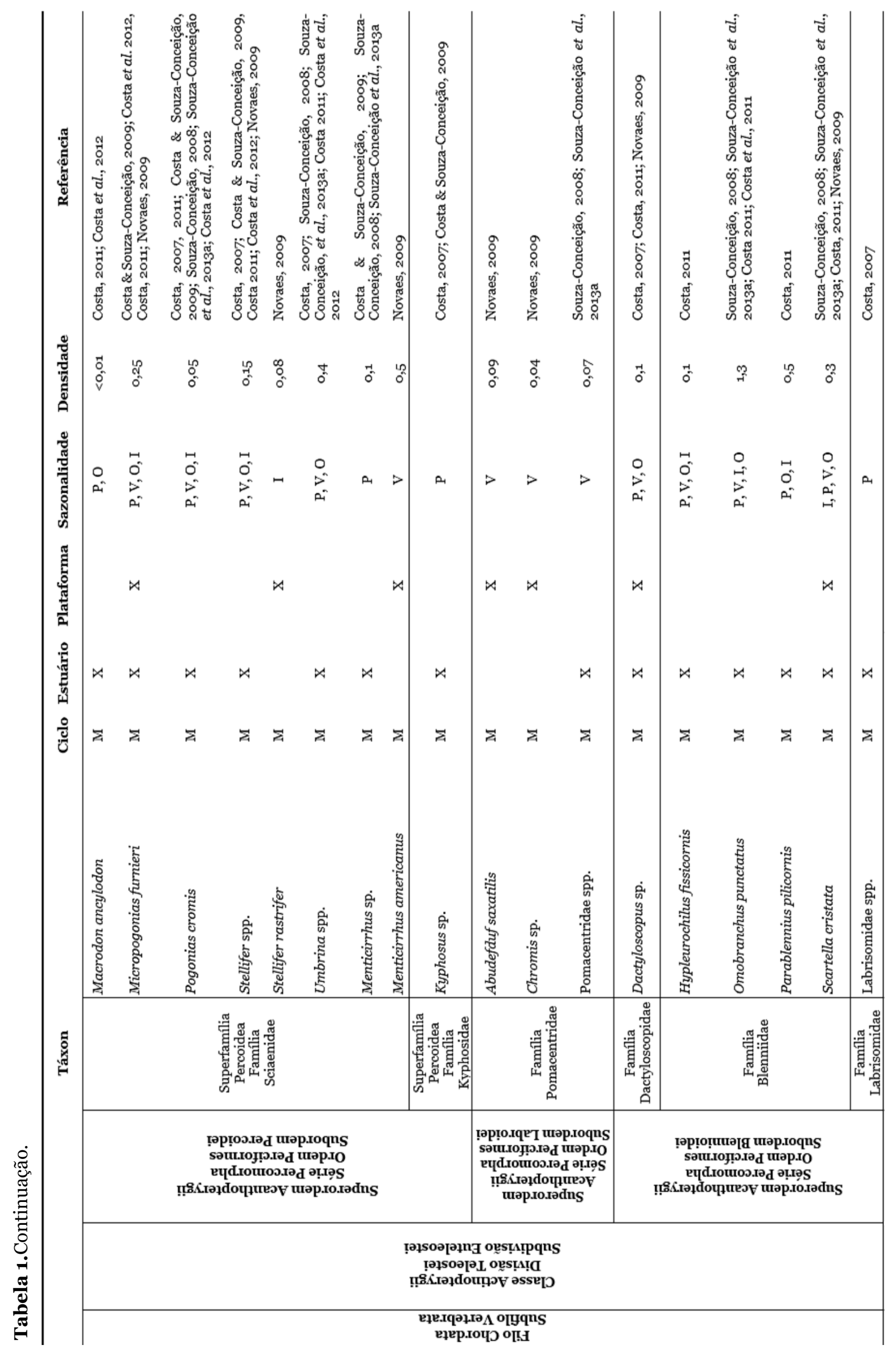

Revista CEPSUL - Biodiversidade e Conservação Marinha, 8: eb2019oo1 


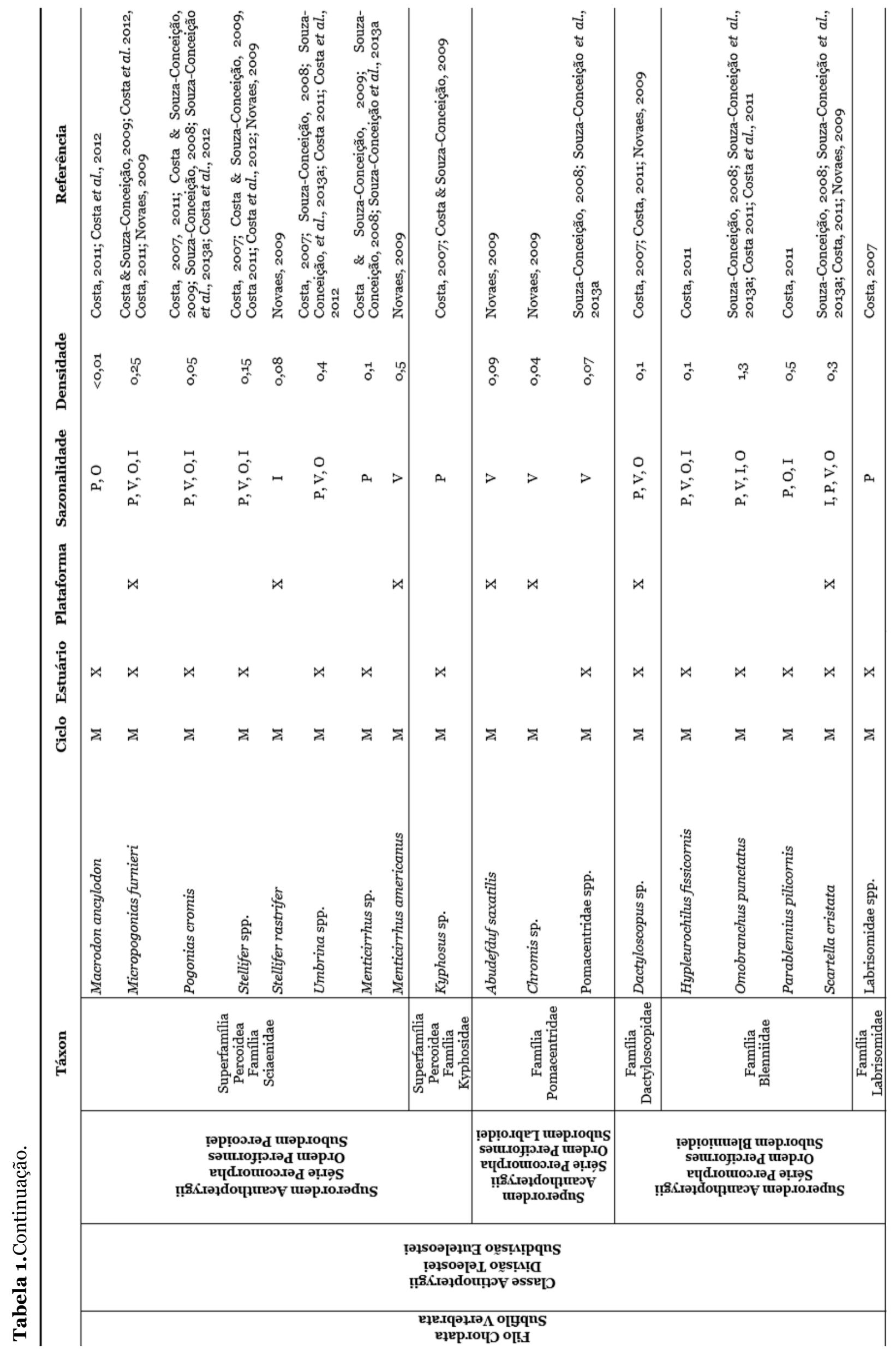

Revista CEPSUL - Biodiversidade e Conservação Marinha, 8: eb2019oo1 


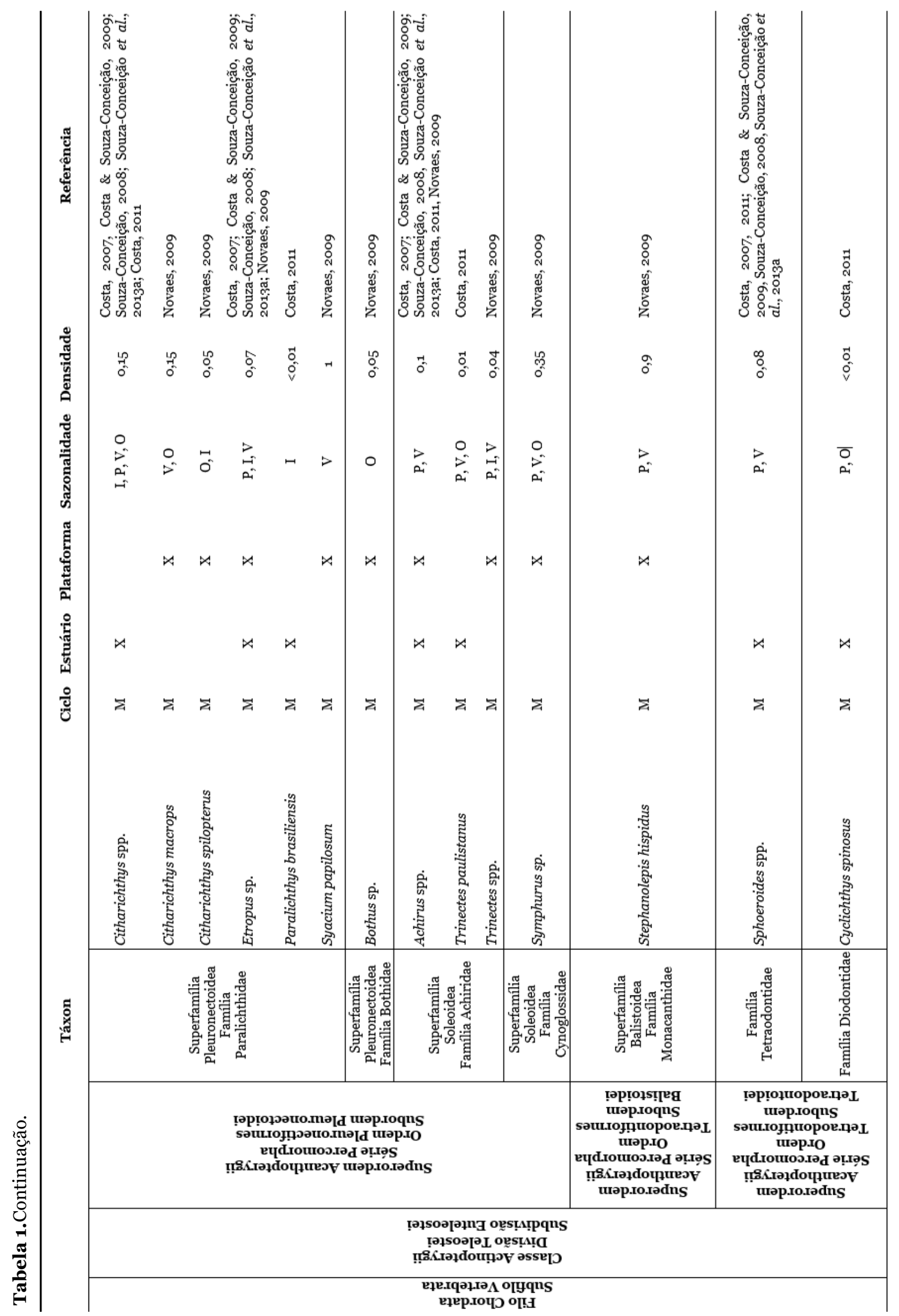

Revista CEPSUL - Biodiversidade e Conservação Marinha, 8: eb2019oo1 


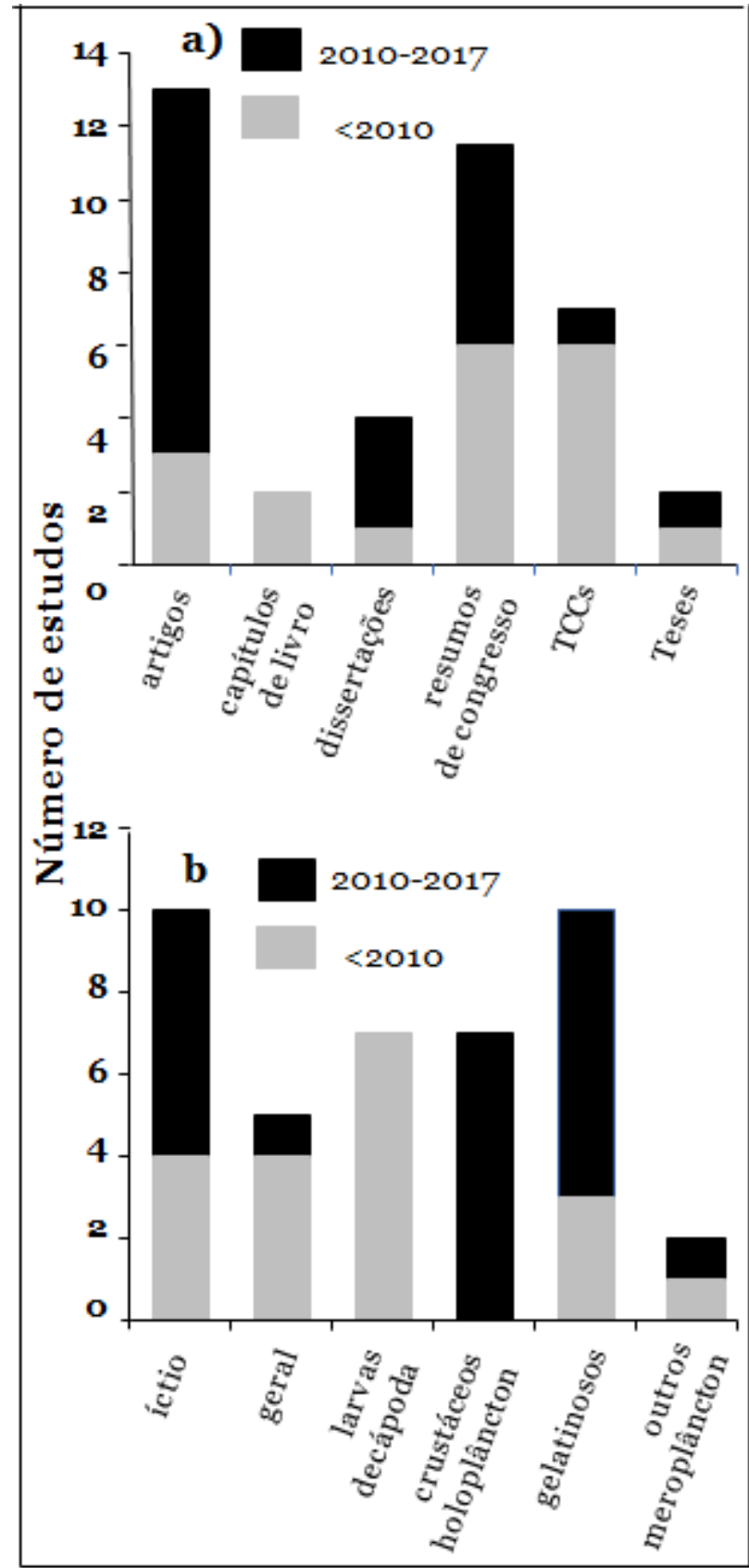

Figura 2. Resumo dos estudos com metazoários planctônicos na Baía da Babitonga e plataforma continental adjacente, de acordo com o tipo de publicação (a) e grupos taxonômicos ou funcionais abrangidos (b). TCCs = trabalhos de conclusão de curso de graduação; ictio = ictioplâncton; geral = comunidade zooplanctônica total; gelatinosos = cnidários, ctenóforos e tunicados; outros meroplâncton = larvas de estomatópodes e poliquetas; crustáceos holoplâncton = copépodes, cladóceros e misídeos.

desde 2010 (Figura 2a), já o número de resumos de congressos manteve-se constante e o número de TCCs diminuiu consideravelmente depois de 2010 (Figura 2a), particularmente após a saída do Prof. Dr. José Maria SouzaConceição da UNIVILLE, um dos pioneiros e principais fomentadores do estudo do plâncton na região (e.g. Souza-Conceição et al., 2007a, b, 2013a, b; Souza-Conceição 2008; Costa \& Souza-Conceição, 2009; Nogueira-Júnior \& Souza-Conceição, 2010).

Composição de espécies, abundância e/ ou biomassa, e dinâmica sazonal e/ou espacial de um determinado grupo, bem como a influência de variáveis abióticas (principalmente temperatura e salinidade) e/ou bióticas (principalmente disponibilidade de alimento) na estruturação das taxocenoses foi a temática da maioria dos estudos. Aspectos como interações tróficas e simbióticas ainda não foram estudados, e outros como reprodução (Oliveira et al., 2010a, b) e produção secundária (Souza, 2013) foram apenas superficialmente analisados com informações restritas tanto em termos taxonômicos, quanto espaciais e temporais. Enquanto variações sazonais foram relativamente bastante estudadas, variações temporais de curta escala (horas, dias, semanas), bem como de longa escala (interanuais, interdecadais) não foram avaliadas na região. Na curta escala, variações com o ciclo das marés são possivelmente as mais relevantes já que as marés influenciam diretamente o gradiente salino que por sua vez é o principal estruturador espacial de comunidades planctônicas estuarinas, conforme já demonstrado na Babitonga para diversos grupos como diatomáceas, dinoflagelados (Brandini et al., 2006), copépodes (Souza, 2013), hidromedusas (Pukanski, 2011), poliquetas (Nogueira-Júnior \& Oliveira, 2017) e ictioplâncton (Costa \& Souza Conceição, 2009; Costa et al., 2012).

Os grupos mais estudados incluem os crustáceos, particularmente as larvas de decápodes antes de 2010 e grupos holoplanctônicos como copépodes e misídeos de 2010 até o presente (Figura 2b), os gelatinosos, principalmente depois de 2010, e o ictioplâncton em ambos períodos (Figura 2b). Entretanto, dentre os estudos com crustáceos apenas dois realizados na plataforma estão disponibilizados sob a forma de artigo em revistas científicas (Marafon-Almeida et al., 2008a; Nunes- 
Domingos \& Resgalla, 2012), sendo que a grande maioria (8 estudos) está na forma de resumos de congressos (e.g. Marafon-Almeida et al., 2007, 2008b) e, portanto, de conteúdo limitado, circulação restrita e difícil acesso. Alguns estudos, principalmente antes de 2010 (Figura 2b), analisaram a comunidade zooplanctônica como um todo apresentando dados de riqueza, diversidade, abundância, biomassa e/ou biovolume total (Alquini, 2003; Brandini et al., 2006; Souza-Conceição et al., 2007a). Trabalhos com outros grupos foram esporádicos (Figura 2b), incluindo poliquetas (Nogueira Júnior \& Oliveira, 2016) e larvas de estomatópodes (Souza-Conceição et al., 2007b), e diversos táxons importantes ainda não foram analisados (veja abaixo na seção "Diversidade zooplanctônica"). Para o ictioplâncton existe uma lacuna em estudos que busquem a identificação dos ovos, apesar da sua importância direta para a identificação das áreas e períodos de desova que podem subsidiar ações de conservação e manejo de espécies exploradas. A falta de estudos nesse sentido é devido, principalmente, a dois fatores: i) material de identificação de ovos é restrito para as espécies que ocorrem na região (Boltovskoy, 1999; Favero et al., 2015), e ii) decréscimo do número de pessoas que trabalham com taxonomia do ictioplâncton.

\section{Diversidade zooplanctônica}

Um total de 261 espécies de metazoários planctônicos foi registrado na Baía da Babitonga e plataforma adjacente, 159 invertebrados e 102 larvas de peixes (Tabela 1). Cordados, crustáceos e cnidários são os grupos com maior número de espécies (Figura 3; Tabela 1). Ainda que em parte isso reflita a quantidade de estudos com os diferentes táxons, esses três grupos em geral estão entre os mais diversos no plâncton marinho (e.g. Boltovskoy, 1981, 1999). Como é típico de regiões costeiras e estuarinas, formas meroplanctônicas predominam em riqueza de espécies (Tabela 1). Entre os cnidários a maioria das espécies registradas na Babitonga são hidromedusas (Figura 3), particularmente as meroplanctônicas das ordens Anthoathecata e Leptothecata, entre os crustáceos predominam as larvas de decápodes e entre os

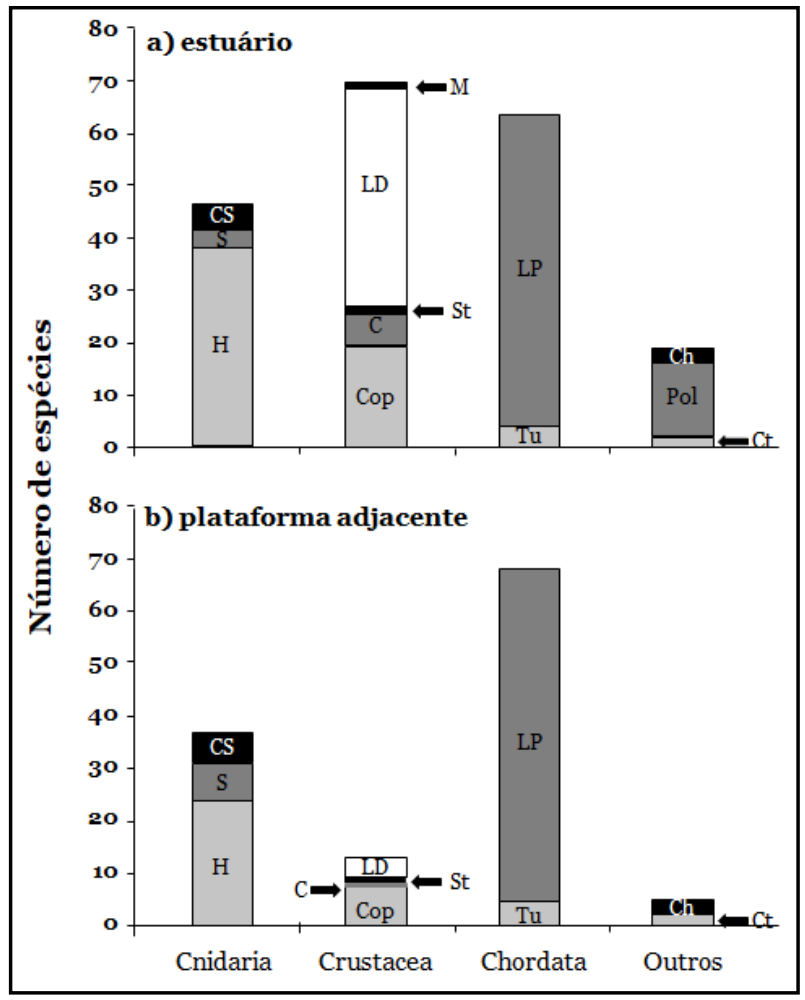

Figura 3. Número de espécies de metazoários planctônicos registradas no setor estuarino (a) e plataforma continental (b) do ecossistema Babitonga. Diferentes cores das barras representam diferentes grupos de acordo com a legenda. $\mathrm{H}=$ hidromedusas; $\mathrm{S}=$ sifonóforos; $\mathrm{CS}=$ cubomedusas e cifomedusas; $\mathrm{Cop}=$ copépodes; $\mathrm{C}=$ cladóceros; $\mathrm{St}=$ larva de estomatópodes; $\mathrm{LD}=$ larvas de decápodes; $\mathrm{M}=$ misídeos; $\mathrm{Tu}=$ tunicados; $\mathrm{LP}=$ larvas de peixes; $\mathrm{Ct}=$ ctenóforos; $\mathrm{Pol}=$ poliquetas; $\mathrm{Ch}=$ quetognatos.

cordados as larvas de peixes (Tabela 1; Figura 3). Diferentemente, as formas holoplanctônicas em geral dominam em abundância. Copépodes, por exemplo, atingem $>30.000$ ind. $\mathrm{m}^{-3}$ no estuário da Babitonga (Souza, 2013), enquanto larvas de decápodes chegam ao máximo de 1.935 ind.m³ (Pandolfo, 2006; Pandolfo et al., 2007; Gonçalves, 2009), hidromedusas meroplanctônicas não ultrapassam 120 ind.m-3 (Nogueira-Júnior et al., 2015), larvas de poliquetas não atingem 1,5 ind.m³ (NogueiraJúnior \& Oliveira, 2017) e larvas de peixes não ultrapassam 60 ind.m-3 (Costa \& SouzaConceição, 2009; Souza-Conceição et al., 2013a).

O número de espécies de invertebrados planctônicos registrados dentro do estuário (141 spp.) é consideravelmente maior que na 
plataforma adjacente (61 spp.), o que não é conclusivo considerando o esforço amostral significativamente menor na plataforma, bem como menor variedade de grupos estudados. Com crustáceos, por exemplo, apenas dois estudos foram realizados na plataforma (Marafon-Almeida et al., 2008a; NunesDomingues \& Resgalla, 2012), enquanto nenhum estudo foi realizado na plataforma com vários outros grupos (e.g. poliquetas e quetognatos)". Em contraste, a diversidade de larvas de peixes, é um pouco maior na plataforma do que no estuário (64 x 60 spp.; Figura 3a, b). Muitas dessas espécies podem habitar ambos os ambientes e dependem dos estuários para o seu desenvolvimento (por exemplo, Micropogonias furnieri e Trachurus lathami). Os estudos de ictioplâncton concentraram-se na região de canal principal do estuário, o que contribui significativamente para o predomínio de espécies marinhas registradas para a região, e que dependem da baía para seu desenvolvimento.

O número de espécies zooplanctônicas registradas na região certamente está subestimado pela ausência de estudos com vários grupos taxonômicos, bem como pelo esforço amostral baixo na região da plataforma adjacente e quase ausente nas regiões mais internas da baía até a entrada dos rios. Portanto, a ocorrência de espécies com afinidades límnicas ainda é pouco conhecida na região. Cladóceros, por exemplo, são muito mais diversificados em água doce do que salgada (Boltovskoy, 1981, 1999), assim é esperado uma diversidade muito maior nessas regiões de salinidades baixas não amostradas. Para alguns grupos nenhuma espécie foi registrada devido à completa ausência de estudos. Esse é o caso dos moluscos, apesar de ocorrência óbvia de larvas de diversas espécies de gastrópodes e bivalves cujos adultos podem ser encontrados em abundância no bentos, muitos dos quais com importância comercial (e.g. Cremer et al., 2006; Tureck et al., nesse volume). Mesmo entre os grupos mais bem estudados localmente, como os crustáceos, cnidários e larvas de peixes, é provável que o número de espécies registradas ainda seja uma subestimativa tanto devido à problemas taxonômicos inerentes a cada grupo, quanto à dificuldade de amostragem de espécies raras, baixo esforço amostral nos setores internos, entre outros.

\section{Espécies exóticas}

Considerando a ausência de estudos históricos com o zooplâncton na Babitonga, bem como para a maioria dos ecossistemas marinhos brasileiros, a detecção de espécies exóticas é difícil. Dentre as 261 espécies de metazoários planctônicos registradas no ecossistema da Babitonga, sete $(\sim 2,7 \%)$ são provavelmente exóticas: as hidromedusas Cnidostoma fallax, Podocoryna loyola, Blackfordia virginica e Moerisia inkermanica, a cifomedusa Phyllorhiza punctata, o copépode Temora turbinata, e o peixe Omobranchus punctatus (Brandini et al., 2006; Haddad \& NogueiraJúnior, 2006; Bardi \& Marques, 2009; Costa et al., 2011; Nascimento et al., 2018).

Podocoryna loyola é considerada provavelmente invasora na região, já que seus pólipos foram detectados em substratos artificiais em Paranaguá apenas a partir de 2007, apesar de estudos locais com hidróides desde os anos 1980 (Haddad et al., 2014). Na Babitonga provavelmente tenha populações estabelecidas. Pólipos (veja Cabral \& Nogueira-Júnior, nesse volume) e medusas (Nogueira-Júnior, 2012) dessa espécie são comuns e abundantes, principalmente no verão quando a atividade reprodutiva é intensificada e as medusas atingem densidade média de $\sim 3,5$ ind.m ${ }^{-3}$ no canal principal (Nogueira-Júnior et al., 2015).

Blackfordia virginica e $M$. inkermanica são espécies tipicamente de regiões estuarinas e águas salobras, consideradas nativas do Mar Negro e com registros de introdução em diversos locais (e.g. Saraber, 1962; Toyokawa \& Fuji, 2015), incluindo Argentina (Genzano et al., 2006) e Brasil (Nogueira-Júnior \& Oliveira 2006; Bardi \& Marques, 2009). B. virginica provavelmente tenha populações estabelecidas na Babitonga ocorrendo em densidades médias de 0,4 ind.m ${ }^{-3}$ durante o verão quando sua abundância é maior (Nogueira-Júnior et al., 2015). Apenas um único indivíduo jovem de $M$. inkermanica foi encontrado na Babitonga (Nogueira-Júnior, 2012). Considerando o hábi- 
to da espécie de ocorrer em águas de baixa salinidade (principalmente $<5$; Nogueira-Júnior \& Oliveira, 2006) em conjunto com o baixo esforço amostral nessa região na Babitonga (Figura 1), não é possível avaliar se $M$. inkermanica mantém populações estabelecidas.

Cnidostoma fallax era considerada endêmica da costa africana do Atlântico (e.g. Kramp, 1961) e desde 2007 tem aparecido em estuários do sul do Brasil como Babitonga (Nogueira-Júnior, 2012), Lagoa dos Patos (Teixeira-Amaral et al., 2017) e Paranaguá (Nascimento et al., 2018), onde pode atingir grande abundância e chegar a representar $>40 \%$ do total de medusas em Paranaguá (Nascimento et al., 2018) e densidades de 11,300 ind. $\mathrm{m}^{-3}$ na Lagoa dos Patos (TeixeiraAmaral et al., 2017). A ausência dessa espécie em estudos pretéritos nesses mesmos estuários sugere que tenha aparecido apenas recentemente, mas pode ter sido omitida devida à escassez de estudos com medusas estuarinas no Brasil (veja Nascimento et al., 2018). Na Babitonga apenas poucos indivíduos foram encontrados e ainda não se sabe se há uma população estabelecida.

Phyllorhiza punctata é uma espécie considerada nativa da Austrália, com vários registros de invasões em regiões costeiras de diversas localidades, principalmente no Atlântico e Mediterrâneo (e.g. Ocaña-Luna et al., 2010; Durgham, 2011), incluindo Brasil. Na Babitonga foi registrada em abundância na entrada do estuário e plataforma adjacente entre 2001 e 2005 (Haddad \& Nogueira-Júnior, 2006), não tendo sido avistada posteriormente (Nogueira-Júnior, 2012). Essa medusa tem picos de ocorrência no Brasil com períodos de desaparecimento (Haddad \& Nogueira-Júnior, 2006; Nagata et al., 2013). Não é claro se isso se deve a pulsos populacionais de longo prazo ou se são invasões recorrentes que não perduram (Nagata et al., 2013).

Temora turbinata foi detectada pela primeira vez no Brasil no estuário do Rio VasaBarris em Sergipe (Araújo \& Montú, 1993), e atualmente é amplamente distribuída em regiões costeiras e estuarinas entre o Pará e o Rio Grande do Sul (Villac et al., 2009). Na Babitonga $T$. turbinata mantém populações estabe- lecidas, sendo amplamente distribuída tanto na plataforma adjacente quanto no estuário (Tabela 1), atingindo maiores densidades no último onde figura entre as espécies mais abundantes com concentrações de até 3.270 ind.m-3 (Brandini et al., 2006; Souza, 2013).

Omobranchus punctatus é nativo do Indo-Pacífico e sua ocorrência em Israel e no Atlântico, incluindo Brasil, é interpretada como resultado de invasões (Gerhardinger et al., 2006; Costa et al., 2011). A espécie tem sido registrada no Brasil desde os anos 2000 em diversos estuários numa ampla variação latitudinal $\left(2-26^{\circ} \mathrm{S}\right)$, incluindo a Babitonga onde a presença de indivíduos adultos (Gerhardinger et al., 2006) e larvas durante quatro anos consecutivos (Costa et al., 2011), indica que a espécie esteja se reproduzindo e completando seu ciclo de vida na região e, portanto, mantendo populações permanentes.

\section{Conectividade, vulnerabilidade e pressões antrópicas}

Considerando o baixo grau de conhecimento que se tem sobre o funcionamento do compartimento zooplanctônico na Babitonga, é difícil apontar as pressões, antrópicas ou não, a que esses organismos estão localmente sujeitos e ainda mais complicado predizer respostas das populações ou alterações na estrutura ou dinâmica da comunidade. Populações planctônicas, por definição, em geral tem alta conectividade com ecossistemas próximos e as trocas são altamente dependentes dos padrões de circulação e da dinâmica de marés, o que é particularmente verdadeiro em estuários (e.g. MeloJúnior et al., 2007). A maioria das espécies é pouco dependente de outros ecossistemas, os tamanhos populacionais em geral são grandes e os tempos de crescimento e reprodução curtos, o que as torna em geral pouco vulneráveis. Provavelmente os maiores impactos estão associados à introdução de espécies exóticas, poluição, bem como alterações físicas na coluna d'água e/ou nos padrões de circulação. Outros fatores que também influenciam as comunidades planctônicas de uma forma geral, mas que ainda não foram analisados localmente são as oscilações oceanográficas de longo prazo (e.g. 
El Niño-La Niña) e mudanças climáticas. Esses eventos exercem forte controle nos padrões oceanográficos e, consequentemente, nos padrões de ocorrência, distribuição e abundância das espécies planctônicas.

As espécies meroplanctônicas, no entanto, dependem diretamente do habitat bêntico, incluindo a disponibilidade de substrato adequado e condições adequadas ao assentamento larval, crescimento e reprodução. Essa interação entre o plâncton e o bentos é particularmente importante considerando que a disponibilidade, abundância e distribuição das larvas, bem como sua dispersão pelas correntes, é um importante fator regulador de populações bênticas incluindo muitas espécies de importância comercial. Para o ictioplâncton, a conectividade entre oceano e estuário é particularmente importante para a manutenção das populações adultas que dependem destes ecossistemas. Muitas das espécies de peixes, que passam suas fases iniciais no plâncton não são residentes do estuário e precisam de outros ecossistemas para manutenção de suas populações, como a corvina Micropogonias furnieri e a palombeta Chloroscombrus chrysurus. Muitas dessas espécies estão sobre-explotadas devido à pressão pesqueira, o que em sinergia com os impactos na condição do habitat e/ou influência de eventos climáticos, podem deixar essas populações ainda mais vulneráveis (veja Herbst et al., nesse volume).

Espécies exóticas comumente tem efeitos negativos para a biodiversidade (Ruiz et al., 1997), como a substituição de espécies nativas, que podem ter sua abundância drasticamente reduzida, inclusive eventualmente sendo localmente extintas. Outro efeito comum causado por espécies invasoras é a modificação da estrutura da comunidade e consequentemente da teia trófica e do funcionamento do ecossistema. No ecossistema Babitonga alguns desses processos podem estar acontecendo. O copépode exótico Temora turbinata é o segundo (Brandini et al., 2006) ou terceiro (Souza, 2013) mais abundante no estuário, enquanto seu congênere nativo, $T$. stylifera, é pouco abundante (Souza, 2013) ou ausente (Brandini et al., 2006; Rodrigues, 2010). Na plataforma adjacente, ao contrário, T. stylifera é mais abundante (Nunes-Domingos \& Resgalla, 2012), corroborando a hipótese que a introdução de $T$. turbinata teria afastado $T$. stylifera para fora da costa (Villac et al., 2009). Como as duas espécies são similares morfológica e ecologicamente, talvez não cause uma alteração drástica na teia trófica e no funcionamento do ecossistema, hipótese que deve ser testada em estudos futuros. De forma análoga, a hidromedusa C. fallax reduziu consideravelmente a abundância da nativa Liriope teraphylla na Baía de Paranaguá, que reiteradamente era a medusa dominante antes do aparecimento de C. fallax e tornou-se a quarta mais abundante (Nascimento et al., 2018). O mesmo talvez não ocorra na Babitonga, já que apenas poucos indivíduos de C. fallax foram encontrados. Ainda assim, essa hidromedusa é capaz de se reproduzir assexuadamente podendo levar a rápidos incrementos populacionais e não se tem informações recentes que possam indicar os níveis atuais de abundância dessa espécie na Babitonga.

No caso das medusas exóticas, um problema em particular são as taxas predatórias e o potencial impacto que podem causar nas populações de presas e/ou competidores, muitos dos quais peixes de importância comercial. Blackfordia virginica, por exemplo, é um predador generalista não seletivo e em estuários em que foi introduzida afeta populações de presas como copépodes e larvas de peixes (Wintzer et al., 2013; Marques et al. 2015), impacto ainda não avaliado na Babitonga ou no Brasil.

A alta carga de poluentes na água do estuário da Babitonga causa redução de fertilidade no misídeo Mysidopsis juniae (Oliveira et al., 2010a), bem como elevadas taxas de mortalidade em Artemia salina (Vaz et al., 2010a). Ainda que esses estudos sejam preliminares e restritos, tanto em termos taxonômicos quanto temporais, eles fornecem uma indicação geral dos efeitos na biota local e sugerem um ecossistema degradado. Mais ensaios abrangendo diferentes grupos taxonômicos, bem como separando diferentes tipos de poluentes são desejáveis para uma melhor delimitação da 
abrangência do problema.

A dragagem do fundo do estuário para manutenção do canal do porto acarreta aumento da turbidez da água que pode influir principalmente no fitoplâncton (Brandini et al., 2006) com provável influência indireta no zooplâncton pela cascata trófica. Adicionalmente, poliquetas adultos tipicamente infaunais podem ser encontrados em suspensão na coluna d'água dentro do estuário da Babitonga, eventos especulativamente associados ao revolvimento do fundo das atividades de dragagem (Nogueira-Júnior \& Oliveira, 2017). Os efeitos da dragagem na turbidez da água e nas comunidades planctônicas bem como nos processos de suspensão de organismos bênticos na coluna d'água devem ser avaliados em detalhes.

Outras perturbações físicas e abertura e/ou fechamento de canais, como já ocorreu no passado com o Canal do Linguado, podem ter um impacto particular nas comunidades planctônicas. Estas modificações acarretam mudanças na dinâmica das correntes dentro do estuário e, portanto, causam alterações nos padrões de transporte e/ou retenção de organismos para dentro e para fora do estuário e, consequentemente, mudanças na composição, abundância e dinâmica do plâncton. Por exemplo, a maré no estuário da Babitonga é caracterizada pela dominância da enchente (Truccolo \& Schettini, 1999). Isso permite a ampla ocorrência de espécies marinhas, incluindo algumas consideradas como típicas da plataforma média/externa, como por exemplo, os sifonóforos Abylopsis tetragona, Diphyes bojani e o quetognato Flaccisagitta enflata, que talvez não adentrassem mais o estuário com condições de circulação (e de salinidade) diferentes, reduzindo assim a diversidade e a complexidade da comunidade.

\section{Conclusões}

A comunidade zooplanctônica foi pouco estudada no ecossistema da Babitonga e mesmo a composição das espécies não é bem conhecida para a maioria dos grupos. Portanto, as 261 espécies registradas certamente estão aquém da real diversidade local. Levantamentos taxonômico-faunísticos ainda são necessários, particularmente dos grupos menos estudados e/ou que incluam amostragem nas regiões mais internas de baixa salinidade $(<10)$ que foram pouco amostradas. Sete espécies são provavelmente exóticas e o monitoramento dessas populações, bem como estudos avaliando em detalhes sua biologia (alimentação, crescimento, reprodução, ciclo de vida, etc.), seriam de grande valor para uma melhor compreensão dos possíveis impactos, particularmente considerando alterações também na comunidade fitoplanctônica devido à presença de espécies exóticas como Coscinodiscus wailesii (Brandini et al., 2006). A presença de espécies exóticas entre os produtores primários (C. wailesii), secundários (T. turbinata) e níveis tróficos superiores (medusas e peixes) pode ser indicativo de que mudanças estruturais estejam ocorrendo na teia trófica local.

Produção secundária, interações tróficas e simbióticas, aspectos reprodutivos, bem como qualquer outro aspecto biológico (e.g. crescimento, ciclo de vida; reprodução) são temas importantes que não foram abordados adequadamente e que devem ser priorizados em estudos futuros, particularmente associando dados de campo em conjunto com experimentos de laboratório e técnicas de modelagem. Na temática da dinâmica das populações e/ou comunidades, é sugerido para estudos futuros focar em variações temporais de curta escala, particularmente seguindo o ciclo das marés em conjunto com análise das taxas de trocas de plâncton entre o estuário e plataforma adjacente, ou abordando variações interanuais e a possível influência de eventos climáticos (e.g. El Niño e La Niña) na composição e distribuição das espécies. Em geral, considerase que a vulnerabilidade da comunidade zooplanctônica é baixa e as maiores pressões provavelmente estejam associadas à poluição, espécies exóticas, distúrbios físicos na coluna d'água e possíveis mudanças nos padrões de circulação e transporte/retenção do plâncton.

\section{Agradecimentos}


Agradecemos a todos da equipe do projeto Babitonga Ativa pelo convite para participar desse volume especial, bem como pelo empenho na realização do projeto e auxílio na obtenção de literatura de difícil acesso. Agradecemos também à Msc. Lorena Silva Nascimento pela leitura crítica e sugestões.

\section{Referências Bibliográficas}

ALQUINI, F. 2003. Estrutura populacional e distribuição espacial da comunidade zooplanctônica no município de Barra do Sul/ SC - Brasil. São Francisco do Sul. 28p. (Trabalho de Conclusão de Curso. Departamento de Ciências Biológicas, UNIVILLE).

ARAÚJO, H. M. P. \& MONTÚ, M. 1993. Novo registro de Temora turbinata (DANA, 1849) (COPEPODA, CRUSTACEA) para águas atlânticas. Nauplius,1: 89-90.

BARDI, J. \& MARQUES, A. C. 2009. The invasive hydromedusae Blackfordia virginica Mayer, 1910 (Cnidaria: Blackfordiidae) in southern Brazil, with comments on taxonomy and distribution of the genus Blackfordia. Zootaxa, 2198: 41-50.

BARDI, J. 2011. Comunidades de hidrozoários (Cnidaria) estuarinos do sudeste e sul do Brasil. São Paulo. 188p. (Tese de Doutorado. Instituo de biociências, Universidade de São Paulo, USP).

BOLTOVSKOY, D. 1981. Atlas del zooplancton del Atlantico Sudoccidental y métodos de trabajo con el zooplancton marino. INIDEP. 933p.

BOLTOVSKOY, D. 1999. South Atlantic Zooplankton. Leiden, Backhuys Publishers. 1706p.

BRANDINI, F. P., ALQUINI, F., PEREIRA, R. B. \& LEITE, R. L. 2006. Abundância e estrutura populacional da comunidade planctônica na Baía da Babitonga: Subsídios para a avaliação de impactos ambientais. In: Cremer, M.J., Morales, P. R. \& Oliveira, T. M. N. (ed.). Diagnóstico Ambiental da Baía da Babitonga. Editora da Univille, Joinville, chap. 4: 112-134.

BRÜNING, A. L. B. 2008. Distribuição e ocorrência de Cnidaria Medusozoa no verão e inver- no, na plataforma continental interna norte de Santa Catarina e Sul do Paraná, Brasil. São Francisco do Sul. 25p. (Trabalho de Conclusão de Curso. Departamento de Ciências Biológicas, UNIVILLE).

COSTA, M. D. P. 2007. Praia de Laranjeiras e pluma do rio Barbosa (baía da Babitonga, Santa Catarina, Brasil): análise quali-quantitativa das comunidades ictioplanctônicas e a influência ambiental. São Francisco do Sul. 58p. (Trabalho de Conclusão de Curso. Departamento de Ciências Biológicas, UNIVILLE).

COSTA, M. D. P. \& SOUZA-CONCEIÇÃO, J. M. 2009. Composição e abundância de ovos e larvas de peixes na baía da Babitonga. PanAm. J. Aquat. Sci., 4: 372-382.

COSTA, M. D. P. 2011. Ictioplâncton da baía da Babitonga (SC, Brasil): Instrumento para a definição de áreas prioritárias para a conservação. Itajaí. 139p. (Dissertação de Mestrado. Centro de Ciências da Terra e do Mar, UNIVALI).

COSTA, M. D. P., SOUZA-CONCEIÇÃO, J. M., SCHWINGEL, P. R. \& SPACH, H. L. 2011. Assessment of larval distribution of invasive Omobranchus punctatus (Valenciennes, 1836) (Pisces: Blenniidae) in a subtropical estuary (Southern Brazil). Aquat. Invasions, 6: 33-38.

COSTA, M. D. P., SCHWINGEL, P. R., SOUZACONCEIÇÃO, J. M. \& SPACH, H. L. 2012. Distribuição espaço-temporal de larvas de Sciaenidae em um estuário subtropical (Santa Catarina, Brasil). Braz. J. Aquat. Sci. Technol., 16: 51-59.

DURGHAM, H. 2011. First Records of Phyllorhiza punctata von Lendenfeld, 1884 (Cnidaria: Rhizostomeae) from the Mediterranean Coast of Syria. Int. J. Ocean Oceanogr., 5: 153-155.

FAVERO, J. M., KATSURAGAWA, M., ZANITEIXEIRA, M. L. \& TURNER, J. T. 2015. Using new tools to identify eggs of Engraulis anchoita (Clupeiformes, Engraulidae). J. Fish Biol., 86: 822-826.

GENZANO, G. N., MIANZAN, H., ACHA, E. M., GAITÁN, E. 2006. First record of the invasive medusa Blackfordia virginica (Hydrozoa: Leptomedusae) in the Río de la Plata estuary, 
Argentina-Uruguay. Rev. Chil. Hist. Nat., 79: 257-261.

GERHARDINGER, L. C., FREITAS, M.O., ANDRADE, A. B. \& RANGEL, C.A. 2006. Omobranchus punctatus (Teleostei: Blenniidae), an exotic blenny in the Southwestern Atlantic. Biol. Invasions, 8: 941-946.

GERHARDINGER, L. C., FREITAS, R.R., CARVALHO, F.G., HERBST, D.F., MERGEN, B., CUNHA, S., CREMER, M.J., VILA-NOVA, D., PFUETZENREUTER, A. 2016. Diagnóstico Socioambiental do Ecossistema Babitonga. 159p. Babitonga Ativa, Editora da Univille, Joinville.

GERHARDINGER, L.C., ZANK, S., CARVALHO, F.G., HERBST, D.S., CUNHA, S. \& CREMER, M.J. 2018. Governabilidade estrutural do subsistema natural do Ecossistema Babitonga (Santa Catarina: Brasil). Revista CEPSUL Biodiversidade \& Conservação Marinha, 7: eb2018001

GONÇALVES, B. T. 2009. Variação espaçotemporal de larvas de Brachyura (CRUSTACEA: DECAPODA) em diferentes áreas da Baía de Babitonga (Santa Catarina, Brasil). São Francisco do Sul. 28p. (Trabalho de Conclusão de Curso. Departamento de Ciências Biológicas, UNIVILLE).

HADDAD, M. A. \& NOGUEIRA-JÚNIOR, M. 2006. Reappearance and seasonality of Phyllorhiza punctata von Lendenfeld 1884 (Cnidaria: Scyphozoa: Rhizostomeae) medusae in southern Brazil. Rev. Bras. Zoo., 23: 824-831.

HADDAD. M. A., BETTIM. A. L. \& MIGLIETTA, M. P. 2014. Podocoryna loyola, n. sp. (Hydrozoa, Hydractiniidae): a probably introduced species on artificial substrate from southern Brazil. Zootaxa, 3796: 494-506.

HARRIS, R. P., WIEBE P. H., LENZ, J., SKJOLDAL, H. R. \& HUNTLEY, M. 200. ICES Zooplankton Methodology Manual. San Diego, Academic Press. 684p.

KRAMP, P.L. 1961. Synopsis of the Medusae of the World. J. Mar. Biol. Assoc. U.K., 40: 1469.

LALLI, C. M. \& PARSONS, T. R. 1997. Biological Oceanography: An Introduction. Oxford, But- terworth Heinemann. 314p.

MARAFON-ALMEIDA, A., SOUZA-CONCEIÇÃO, J.M. \& PANDOLFO, S.P. 2007. Distribuição de decápodes planctônicos (Crustacea: Decapoda) no inverno de 2004 e verão de 2005 , na plataforma continental interna norte catarinense e sul paranaense. In: XII Congresso Latino-Americano de Ciências do Mar - COLACMAR, 2007, Florianópolis. p.25-26.

MARAFON-ALMEIDA, A. SOUZA-CONCEIÇÃO, J. M. \& PANDOLFO, P. S. V. 2008a. Distribuição e abundância de larvas de três espécies de Penaeídeos (Decapoda) na plataforma continental interna adjacente à Baía da Babitonga, Sul do Brasil. Pan-Am. J. Aquat. Sci., 3: 340-350.

MARAFON-ALMEIDA, A. MASUNARI, S., SOUZA-CONCEICAO, J. M. \& PANDOLFO, P. S. V. 2008b. Densidade das larvas de Menippe nodifrons (Decapoda: Xanthidae) ocorrentes no zooplâncton da Baía da Babitonga, SC, Brasil. In: V Congresso Brasileiro sobre Crustáceos, 2008. Gramado: Editora Nomemarketing, 5: 95-95.

MARAFON-ALMEIDA, A. 2009. Distribuição espaço-temporal de decápodes meroplanctônicos na Baía da Babitonga, SC, Brasil. Curitiba. 62p. (Dissertação de Mestrado. Setor de Ciências Biológicas, UFPR).

MARQUES, F., CHAINHO, P., COSTA, J. L., DOMINGOS, I. \& ANGÉLICO, M. M. 2015. Abundance, seasonal patterns and diet of the non-native jellyfish Blackfordia virginica in a Portuguese estuary. Estuar. Coast. Shelf. Sci., 167: 212-219.

MELO-JÚNIOR, M. D. J., PARANAGUÁ, M. N., SCHWAMBORN, R., LEITÃO, S. N. \& EKAU, W. 2007. Fluxes of zooplankton biomass between a tidal estuary and the sea in Northeastern Brazil. Braz. J. Ocean., 55: 239-249.

NAGATA, R. M., SANTOS, L., STAMPAR S. N., NOGUEIRA-JÚNIOR, M., MORANDINI A. C. 2013. Phyllorhiza punctata in Brazilian coast: population oscillations or recurrent invasions? In: Proceedings of the Fourth International Jellyfish Blooms Symposium, Hiroshima, p. 128.

NASCIMENTO, L. S., NOGUEIRA-JÚNIOR, M., MACÊDO, E.V. \& BERSANO, J.G. 2018. Bio- 
diversity of planktonic hydrozoans from a subtropical estuary: evidence of assemblage structure change J. Mar. Biol. Assoc. U.K., doi:10.1017/Soo25315418000486

NOGUEIRA-JÚNIOR, M. \& OLIVEIRA, J. S. 2006. Moerisia inkermanica PaltschikowaOstroumova (Hydrozoa; Moerisidae) e Blackfordia virginica Mayer (Hydrozoa; Blackfordiidae) na Baía de Antonina, Paraná, Brasil. Pan-Am. J. Aquat. Sci., 1: 35-42.

NOGUEIRA-JÚNIOR, M., ROBERT, M. C. \& HADDAD, M. A. 2006. Ocorrência massiva de Aurelia sp. no sul do Brasil. Uma espécie nova?. In: XXVI Congresso Brasileiro de Zoologia, 2006, Londrina.

NOGUEIRA-JÚNIOR, M. \& SOUZACONCEIÇÃO, J. M. 2010. Seasonal distribution and size class composition of the scyphomedusae Chrysaora lactea (Semaeostomeae) and Lychnorhiza lucerna (Rhizostomeae) in a subtropical estuary in Southern Brazil. In: Third International Jellyfish Blooms Symposium, p. 82.

NOGUEIRA-JÚNIOR, M. 2012. Gelatinous zooplankton fauna (Cnidaria, Ctenophora and Thaliacea) from Baía da Babitonga (southern Brazil). Zootaxa, 3398:1-21.

NOGUEIRA-JÚNIOR, M., RODRIGUEZ, C. S., MIANZAN H. W., HADDAD, M. A. \& GENZANO, G. 2013. Description of a new hydromedusa from the southwestern Atlantic Ocean, Bougainvillia pagesi sp. nov. (Cnidaria, Hydrozoa, Anthoathecata). Mar. Ecol., 34:113-122.

NOGUEIRA-JÚNIOR, M., PUKANSKi, L. E. M. \& SOUZA-CONCEIÇÃO, J. M. 2015. Mesh size effects on assessments of planktonic hydrozoan abundance and assemblage structure. J. Mar. Syst., 144:117-126.

NOGUEIRA-JÚNIOR, M. \& OLIVEIRA, V.M. 2017. Strategies of plankton occupation by polychaete assemblages in a subtropical estuary (south Brazil). J. Mar. Biol. Assoc. U.K., 97(8): 1651-1661.

NOVAES, L. D. 2009. Comunidade ictioplanctônica na Plataforma Continental Interna adjacente à baía da Babitonga: uma abordagem espaço-sazonal. São Francisco do Sul. 42p.
(Trabalho de Conclusão de Curso. Departamento de Ciências Biológicas, UNIVILLE).

NUNES-DOMINGOS, R. \& RESGALLA-JÚNIOR, C. 2012. The zooplankton of Santa Catarina continental shelf in southern Brazil with emphasis on Copepoda and Cladocera and their relationship with physical coastal processes. Lat. Am. J. Aquat. Res., 40: 893-913.

OCAÑA-LUNA, A., SÁNCHEZ-RAMÍREZ, A., AGUILAR-DURÁN, R. 2010. First record of Phyllorhiza punctata von Lendenfeld, 1884 (Cnidaria: Scyphozoa, Mastigiidae) in Mexico. Aquat. Invasions, 5: S70-S84.

OLIVEIRA, T. M. N., VAZ, C., MATIAS, W. G., BÖHM, R. F. S., SPITZNER E.C., SIMM, M. \& BARROS, V. G. 2010a. Water quality assessment using a reproduction toxicity test with Mysidopsis juniae as a bioindicator. Toxicol. Lett., 196S: S121.

OLIVEIRA, T. M. N., Vaz, C., KLEINE, T., BÖHM, R. F. S. \& MATIAS, W. G. 2010b. Effect of temperature and salinity in Mysidopsis juniae reproduction. Toxicol. Lett., 196S: S121.

PANDOLFO, P. S. V. 2006. Variação temporal e influência das variáveis ambientais na distribuição de DECAPODA planctônicos e larvas de camarões PENAEIDAE em três áreas de pesca na Baía da Babitonga, São Francisco do Sul, Santa Catarina, Brasil. São Francisco do Sul. 24p. (Trabalho de Conclusão de Curso. Departamento de Ciências Biológicas, UNIVILLE).

PANDOLFO, P. S. V., SOUZA-CONCEICAO, J. M., MARAFON-ALMEIDA, A. 2007. Distribuição espacial de decápodes planctônicos entre outubro de 2004 e setembro de 2005 na porção central da Baía da Babitonga - SC. In: XII Congresso Latino-Americano de Ciências do Mar - COLACMAR, 2007, Florianópolis. p.26.

PUKANSKI, L. E. M. 2011. Dinâmica populacional das hidromedusas Liriope tetraphyla (Trachymedusae) e Blackfordia virginica (Leptothecata) na Baía da Babitonga - litoral norte de Santa Catarina, Brasil. Curitiba. 38p. (Dissertação de Mestrado. Departamento de Zoologia, UFPA).

PUKANSKI, L. E. M., HADDAD, M. A., NOGUEI- 
RA-JÚNIOR, M. \& SOUZA-CONCEIÇÃO, J. M. 2010. Distribuição espaço-temporal das hidromedusas: Liriope tetraphylla (Trachymedusae) e Blackfordia virginica (Leptothecata) na Baía da Babitonga, Santa Catarina. In: Resumos Expandidos do IV Congresso Brasileiro de Oceanografia, Rio Grande. p. 1259-1262.

RESGALLA-JÚNIOR, C. 2011. The holoplankton of the Santa Catarina coast, southern Brazil. An. Acad. Bras. Ciênc., 83: 575-588.

RODRIGUES, T. T. S. 2010. Variação sazonal de Temora turbinata e Temora stylifera (COPEPODA, CALANOIDA, TEMORIDAE) ao longo da área portuária de São Francisco do Sul (SC). São Francisco do Sul. 22p. (Trabalho de Conclusão de Curso. Departamento de Ciências Biológicas, UNIVILLE).

RUIZ, G. M., CARLTON J. T., GROSHOLZ E. D. \& HINES A. H. 1997. Global invasions of marine and estuarine habitats by nonindigenous species: mechanisms, extent, and consequences. Am. Zool., 37: 621-632.

SCHROEDER, R., BRANCO, J. O., FREITAS F. \& RESGALLA C. 2014. Preliminary assessment of the jellyfish bycatch captured off southern and southeastern Brazil. Lat. Am. J. Aquat. Res., 42: 289-300.

SARABER, J.G.A.M. 1962. Ostroumovia inkermanica in the Netherlands. Beaufortia, 100 (9): 117-120.

SCHETTINI, C.A.F., TRUCCOLO, E.C., RESGALLA, C., RÖRIG, L.R. \& KUROSHIMA, K.N. 2002. O sistema estuarino da baía da Babitonga. In: KNIE, J.L.W. (ed.). Atlas ambiental da região de Joinville - Complexo hídrico da baía da Babitonga, chap. 6: 113118.

SMITH, D. L. \& K. B. JOHNSON. 1996. A Guide to marine Coastal Plankton and Marine Invertebrate Larvae. Iowa, Kendall/Hunt Publishing Company. 161p.

SOUZA, D. P. 2013. Composição e biomassa de COPÉPODES na Baía da Babitonga - SC, Brasil. Curitiba. 38p. (Dissertação de Mestrado. Centro de Estudos do Mar, UFPR).

SOUZA-CONCEIÇÃO, J. M. 2008. Praias estuarinas como habitat de criação para estágios iniciais de peixes na ilha de São Francisco do Sul (baía da Babitonga, Santa Catarina). Curitiba. 198p. (Tese de Doutorado. Setor de Ciências Biológicas, UFPR).

SOUZA-CONCEICAO, J. M., CAMACHO, F. P., MARAFON-ALMEIDA, A., COSTA, M. D. P., BORDIN, D., SPACH, H. L., PANDOLFO, P. S. V., FRISANCO, D., DOGE, F. S., SERENA, J. L., DUARTE, L. N. \& SILVA, L. C. F. C. 2007a. Distribuição espaço-temporal da clorofila-a e do biovolume de zooplâncton empraias estuarinas na Baía da Babitonga, Sul do Brasil. In: XII Congresso LatinoAmericano de Ciências do Mar - COLACMAR, 2007, Florianópolis, p. 366.

SOUZA-CONCEICAO, J. M., MARAFONALMEIDA, A., PANDOLFO, P. S. V., FUSINATO, L. F. P. 2007b. Distribuição de larvas de Stomatopoda (Crustacea: Malacostraca) entre inverno e verão, na plataforma continental interna e na região estuarina da Baía da Babitonga, Brasil. In: XII Congresso Latino-Americano de Ciências do Mar - COLACMAR, 2007, Florianópolis, p. 125.

SOUZA-CONCEIÇÃO, J. M., SPACH, H. L., COSTA, M. D. P. \& BORDIN, D. 2013a. Variação espaço-temporal do ictioplâncton em praias estuarinas da baía da Babitonga, Santa Catarina, Brasil. Biotemas, 26: 129-141.

SOUZA-CONCEIÇÃO, J. M., COSTA, M. D. P., SPACH, H. L. \& SCHWINGEL, P. R. 2013b. Microdesmus longipinnis (Gobioidei, Microdesmidae): occurrence, abundance and sampling in a subtropical estuary. Neotrop. Biol. Conserv., 8: 111-114.

SUMICH, J. L. 1996. An Introduction to the Biology of Marine Life. Wm. C. Brown Publishers. 461p.

TEIXEIRA-AMARAL, P., AMARAL, W.J.A., ORTIZ, D.O., AGOSTINI, V. O. \& MUXAGATA, E. 2017. The mesozooplankton of the Patos Lagoon Estuary, Brazil: trends in community structure and secondary production. Mar. Biol. $\quad$ Res., 13 : 48-61. doi:10.1080/17451000.2016.1248850"b

TOYOKAWA, M. \& FUJII, N. 2015. First record of two invasive hydromedusae Maeotias marginata (Modeer, 1791) (Hydrozoa: Limnomedusae) and Blackfordia virginica May- 
er, 1910 (Hydrozoa: Leptomedusae) in Japan.

Plank. Benth. Res., 10: 215-219.

TRUCCOLO, E. C. \& SCHETTINI, C. A. F. 1999. Marés astronômicas na Baía da Babitonga, SC. Notas Téc. Facimar, 3: 57-66.

VAZ, C., OLIVEIRA, T. M. N. D., BÖHM, R. F. S., SPITZNER, E. C., SIMM, M. \& BARROS, V. G. 2010a. Use of Artemia salina to identify sites with risk of contamination in the waters of Babitonga Bay. Toxicol. Lett., 196S:S120.

VAZ, C., MATIAS, W. G., OLIVEIRA, T. M. N. D., BÖHM, R. F. S., SPITZNER, E. C., SIMM, M. \& BARROS, V. G. 2010b. Method definition and application of a pilot assay for a life-cycle toxicity test under semi-static conditions for the marine organism Mysidopsis juniae. Toxicol. Lett., 196S:S121.

VIEIRA, L. R., GUILHERMINO, L. \& MORGADO, F. 2015. Zooplankton structure and dynamics in two estuaries from the Atlantic coast in relation to multi-stressors exposure. Estuar. Coast. Shelf Sci., 167: 347-367.

VILLAC, M.C., LOPES, R.M., RIVERA, I.N.G., BASSANELLO, R.T., CUNHA, D.R., MARTINELLI-FILHO, J.E., SANTOS, D.E. 2009. Plâncton. In LOPES, R.M. (ed.). Informe sobre as espécies exóticas invasoras marinhas no Brasil. Ministério do Meio Ambiente, Brasília, chap. 4. 39-104.

WINTZER, A. P., MEEK, M. H. \& MOYLE, P. B. 2013. Abundance, size, and diel feeding ecology of Blackfordia virginica (Mayer, 1910), a non-native hydrozoan in the lower Napa and Petaluma Rivers, California (USA). Aquat. Invasions 8:147-156. 